\title{
Influence of Surface Topography on the Critical Carbon Dioxide Level Required for the Formation of a Modern Snowball Earth
}

\author{
YONGGANG LIU \\ Department of Atmospheric and Oceanic Sciences, School of Physics, Peking University, Beijing, China \\ W. RICHARD PELTIER \\ Department of Physics, University of Toronto, Toronto, Ontario, Canada \\ JUN YANG AND YONGYUN HU \\ Department of Atmospheric and Oceanic Sciences, School of Physics, Peking University, Beijing, China
}

(Manuscript received 5 December 2017, in final form 5 August 2018)

\begin{abstract}
The influence of continental topography on the initiation of a global glaciation (i.e., snowball Earth) is studied with both a fully coupled atmosphere-ocean general circulation model (AOGCM), CCSM3, and an atmospheric general circulation model (AGCM), CAM3 coupled to a slab ocean model. It is found that when the climate is very cold, snow cover over the central region of the Eurasian continent decreases when the atmospheric $\mathrm{CO}_{2}$ concentration $\left(p \mathrm{CO}_{2}\right)$ is reduced. In the coupled model, this constitutes a negative feedback due to the reduction of land surface albedo that counteracts the positive feedback due to sea ice expansion toward the equator. When the solar insolation is $94 \%$ of the present-day value, Earth enters a snowball state when $p \mathrm{CO}_{2}$ is $\sim 35 \mathrm{ppmv}$. On the other hand, if the continents are assumed to be flat topographically (with the global mean elevation as in the more realistic present-day case), Earth enters a snowball state more easily at $p \mathrm{CO}_{2}=\sim 60 \mathrm{ppmv}$. Therefore, the presence of topography may increase the stability of Earth against descent into a snowball state. On the contrary, a snowball Earth is found to form much more easily when complex topography is present than when it is not in CAM3. This happens despite the fact that the mid- to high-latitude climate is much warmer (by $\sim 10^{\circ} \mathrm{C}$ ) when topography is present than when it is not. Analyses show that neglecting sea ice dynamics in this model prevents the warming anomaly in the mid- to high latitudes from being efficiently transmitted into the tropics.
\end{abstract}

\section{Introduction}

Geological and geochemical evidence suggest that several global glaciations, termed snowball Earth events, have occurred during the Neoproterozoic era of Earth history (1000-540 Ma) (Ma = million years ago; Hoffman and Schrag 2000, 2002; Hoffman et al. 1998, 2017; Kirschvink 1992). During these events, evidence derived from glacial deposits suggests that the continents at low latitudes were likely completely covered by thick ice sheets, leading many to assume that the oceans must also have been completely covered by sea ice based on indirect evidence (e.g., Hoffman et al. 1998). Nevertheless some climate simulations (in which continental ice sheets have been explicitly considered) have been

\footnotetext{
Corresponding author: Yonggang Liu,ygliu@pku.edu.cn
}

invoked to show that it is possible that the tropical oceans remained free of sea ice (e.g., Hyde et al. 2000; Liu and Peltier 2010; Liu et al. 2016; Peltier et al. 2007). Therefore, the terms "hard snowball" and "soft snowball/ slushball" have been used to distinguish between snowball states in which the oceans were completely or only partially covered by sea ice, respectively. In this paper, the term "hard snowball Earth" will always be intended when the terms "snowball Earth" or "snowball state" are employed, unless otherwise specified to the contrary. The conditions under which Earth would be expected to enter a snowball state have received a great deal of attention (Baum and Crowley 2001; Budyko 1969; Chandler and Sohl 2000; Feulner and Kienert 2015; Fiorella and Poulsen 2013; Jenkins and Frakes 1998; Jenkins and Smith 1999; Lewis et al. 2003, 2004, 2007; Liu et al. 2013; Peltier et al. 2004; Pollard and 
Kasting 2004; Poulsen and Jacob 2004; Poulsen et al. 2001, 2002; Voigt and Marotzke 2010; Voigt and Abbot 2012; Voigt et al. 2011; Yang et al. 2012a,b,c), but large uncertainty remains.

Many processes have been previously studied and shown to have an influence on the critical carbon dioxide level $\left(p \mathrm{CO}_{2}\right)$ for snowball Earth formation: for example, Earth's rate of axial rotation (Jenkins and Frakes 1998) and the obliquity of the spin axis with respect to the plane of the ecliptic (Chandler and Sohl 2000; Donnadieu et al. 2002; Jenkins 2000; Oglesby and Ogg 1999), ocean dynamics (Chandler and Sohl 2000; Jenkins and Smith 1999; Poulsen and Jacob 2004; Poulsen et al. 2001), cloud feedback (Abbot et al. 2012; Hyde et al. 2000; Poulsen and Jacob 2004; Voigt and Marotzke 2010; Yang et al. 2012b), sea ice dynamics (Abbot et al. 2010; Lewis et al. 2007; Poulsen and Jacob 2004; Voigt and Abbot 2012; Yang et al. 2012a), sea glaciers (Goodman 2006; Goodman and Pierrehumbert 2003; Pollard and Kasting 2005, 2006), carbon cycle (Liu and Peltier 2011; Peltier et al. 2007; Schrag et al. 2002), continental ice sheets (Baum and Crowley 2001; Hyde et al. 2000; Liu and Peltier 2010; Liu et al. 2016; Peltier et al. 2007), and the distribution of continents and oceans (Donnadieu et al. 2004; Fiorella and Poulsen 2013; Lewis et al. 2003; Liu and Peltier 2010; Liu et al. 2013; Pollard and Kasting 2004; Poulsen et al. 2002; Voigt et al. 2011). In the literature, determining the critical $p \mathrm{CO}_{2}$ for snowball Earth formation has been often stated as determining the initiation of a snowball Earth (e.g., Chandler and Sohl 2000; Voigt and Marotzke 2010). We will follow this convention in the discussion herein. Among the wide range of factors, sea ice dynamics have been shown to have very large impact on snowball Earth initiation. For example, Voigt and Abbot (2012) showed using an AOGCM, ECHAM5/MPI$\mathrm{OM}$, that a hard snowball Earth formed when $p \mathrm{CO}_{2}$ was lowered to around $204 \mathrm{ppmv}$, but it formed at much lower $p \mathrm{CO}_{2}(=2 \mathrm{ppmv})$ if sea ice dynamics were disabled. Our purpose in the present paper is to investigate the influence of topography on the initiation of a snowball Earth utilizing the present-day continental configuration, but we will also demonstrate that different roles for topography can be inferred depending on whether sea ice dynamics are explicitly represented in the model.

Little attention has been paid to the influence of continental topography on the snowball Earth initiation previously. Jenkins and Frakes (1998) considered a north-south mountain chain added to the west coast of a supercontinent, and found it to be most probably unimportant to the initiation of a snowball Earth. A similar conclusion was reached by Romanova et al. (2006). Fiorella and Poulsen (2013) considered the influence of the present-day topography on the initiation of snowball
Earth with the AGCM CAM3 coupled to a slab ocean. They found that a snowball Earth was initiated more easily in the presence of continental topography. Here we will essentially repeat the simulations of Fiorella and Poulsen (2013) but with the influences of ocean and sea ice dynamics included. As will be described in what follows, sea ice dynamics is an extremely important determinant of the sensitivity of climate to topographic changes. Such an increase in realism of the simulations will lead us to the opposite conclusion from that of Fiorella and Poulsen (2013) concerning the influence of continental topography on snowball Earth onset.

In previous studies of snowball Earth initiation with AOGCM CCSM3, Yang et al. (2012a,b) adopted the present-day continental distribution and topography, whereas Liu et al. (2013) adopted a Neoproterozoic continental distribution with flat surface (no topography). They obtained a significantly different critical $p \mathrm{CO}_{2}$ below which a hard snowball Earth formed (i.e., $\sim 20$ ppmv in the former case but $60-100 \mathrm{ppmv}$ in the latter). Moreover, the zonal-mean sea ice edge was found to reach the very low value of $\sim 15^{\circ}$ latitude in Yang et al. (2012a,b) without triggering the runaway sea ice albedo feedback that leads to hard snowball state formation. However, the sea ice edge (referred to as the critical sea ice edge hereafter) could reach only $\sim 24^{\circ}$ latitude in the analyses of Liu et al. (2013). Such a difference is unlikely due to the different continental distribution between the two studies because two quite different variations of continental distribution (appropriate for 720 and $570 \mathrm{Ma}$, respectively) were investigated in Liu et al. (2013). We therefore suspect that the present-day topography employed in Yang et al. (2012a,b) may have been responsible for the difference in the critical $p \mathrm{CO}_{2}$ and location of the sea ice edge, and the present study is intended to shed light on this issue.

Our ultimate goal is to understand how continental topography may influence the critical $p \mathrm{CO}_{2}$ during the Neoproterozoic snowball Earth events. However, little information on the Neoproterozoic surface topography is available. Since the snowball Earth initiation for modern continental configuration has been well studied (Chandler and Sohl 2000; Fiorella and Poulsen 2013; Voigt and Marotzke 2010; Yang et al. 2012a,b,c), it is advisable to start by understanding how modern topography, which is well observed, may influence the snowball Earth initiation. This is what we do herein. Because the fundamental physical processes that come into play when the influence of continental topography is included in the coupled climate model are the same for different time periods in the past, useful information is expected to be forthcoming from the following analyses of snowball formation under modern conditions. 
TABLE 1. Summary of CCSM3 simulations.

\begin{tabular}{|c|c|c|c|c|c|c|c|c|}
\hline \multirow{2}{*}{\multicolumn{2}{|c|}{$p \mathrm{CO}_{2}(\mathrm{ppmv})$}} & \multicolumn{4}{|c|}{ With topography (WT) } & \multicolumn{3}{|c|}{ No topography (NT) } \\
\hline & & 140 & 70 & 40 & 35 & 140 & 70 & 60 \\
\hline Global surface & erature $\left({ }^{\circ} \mathrm{C}\right)$ & -14.9 & -19.0 & -23.5 & -40.0 & -12.8 & -21.1 & -40.0 \\
\hline Global SST ( & & -10.5 & -15.0 & -19.9 & - & -9.1 & -17.3 & - \\
\hline Sea ice fracti & & 47.4 & 53.9 & 64.0 & 100.0 & 44.8 & 56.8 & 100.0 \\
\hline \multirow[t]{2}{*}{ Sea ice edge } & $\mathrm{SH}\left({ }^{\circ} \mathrm{S}\right)$ & 33.3 & 29.0 & 21.0 & 0.0 & 33.6 & 24.5 & 0.0 \\
\hline & $\mathrm{NH}\left({ }^{\circ} \mathrm{N}\right)$ & 26.5 & 24.0 & 18.2 & 0.0 & 31.2 & 24.0 & 0.0 \\
\hline Planetary alb & & 0.465 & 0.479 & 0.496 & 0.58 & 0.455 & 0.488 & 0.58 \\
\hline \multicolumn{2}{|c|}{ Column water vapor $\left(\mathrm{kg} \mathrm{m}^{-2}\right)$} & 4.05 & 3.05 & 2.19 & 0.47 & 4.82 & 2.76 & 0.47 \\
\hline
\end{tabular}

\section{Model description and experiments}

The NCAR CCSM3 model (Collins et al. 2006) is employed for the current study. Both the atmospheric module and the land module are run at a horizontal resolution of $\mathrm{T} 31\left(\sim 3.75^{\circ} \times 3.75^{\circ}\right)$, and both the ocean and sea ice modules at "gx3v5" (with 100 and 116 grid points in the zonal and meridional directions, respectively). In the vertical, the atmosphere and ocean are resolved on 26 and 25 levels, respectively. The four modules are linked through a flux coupler with no flux corrections between the modules. The albedo of bare sea ice is dependent on ice thickness and ice surface temperature. The albedo for cold $\left(T_{s}<-1^{\circ} \mathrm{C}\right)$ and thick sea ice $(>0.5 \mathrm{~m})$ is 0.68 in the visible band and 0.30 in the near-infrared. It decreases with decreasing thickness according to an inverse tangent relation, and with higher temperature due to the formation of melt ponds at the surface (Briegleb et al. 2004). The albedo of snow on ice is tracked separately. Its values are 0.96 in the visible band and 0.68 in the near-infrared for cold snow, and these values decrease linearly with temperature to minimum values of 0.86 and 0.53 , respectively, at $0^{\circ} \mathrm{C}$.

The present-day continental distribution is used but vegetation, lakes, and wetlands are removed; the soil color is changed to a uniform value of 1 (which is the lightest available in the model, with albedos of 0.24 and 0.48 for the visible and near-infrared bands, respectively when the soil is dry; the values are reduced by half when the soil is saturated with water); soil texture is fixed to that of loam (an average soil) (Rosenbloom et al. 2011); and the aerosol is assumed to have a spatially uniform and time-invariant distribution (specified by an optical depth of 0.12), the same as assumed in Liu et al. (2013). Two sets of experiments are carried out, one with the present-day topography (referred to as WT hereafter) and the other without (referred to as NT). The elevation of all continents above sea level is set to $400 \mathrm{~m}$ for the latter. In this circumstance, the global mean elevations of the WT and NT cases are almost the same (231.5 vs
$251.1 \mathrm{~m}$ for the resolution used here), so that the effect of topographic variations can be isolated.

In all experiments, the solar constant is fixed at 94\% (Bahcall et al. 2001) of the present-day value $\left(1367 \mathrm{~W} \mathrm{~m}^{-2}\right)$ with Earth's orbit set to that of year 1990, and the atmospheric concentrations of $\mathrm{CH}_{4}\left(p \mathrm{CH}_{4}\right)$ and $\mathrm{N}_{2} \mathrm{O}\left(p \mathrm{~N}_{2} \mathrm{O}\right)$ are assumed to be 805.6 and $276.7 \mathrm{ppbv}$, respectively. For each set of the experiments, we run the model to equilibrium at a series of $p \mathrm{CO}_{2}$ values. The high end of the $p \mathrm{CO}_{2}$ values is $140 \mathrm{ppmv}$, while the low end differs for the two sets of experiments because they reach a snowball Earth state at different $p \mathrm{CO}_{2}$. The properties of the sequence of model runs to be analyzed are listed in Table 1.

For the WT experiment, the model is initialized with a preindustrial climate state with $p \mathrm{CO}_{2}$ set to 140 ppmv. Figure 1a shows the evolution of global mean surface temperature for this case. The equilibrium state of this simulation was then used to initialize the NT simulations with the same $p \mathrm{CO}_{2}$ (e.g., the case shown in Fig. 1c). The simulations with lower $p \mathrm{CO}_{2}$ (e.g., $70 \mathrm{ppmv}$ ) are normally initialized from the respective equilibrium state of the 140-ppmv simulations (e.g., Fig. 1d). One exception is the WT simulation with $p \mathrm{CO}_{2}=70 \mathrm{ppmv}$, which was initialized from the equilibrium state of the WT simulation with $p \mathrm{CO}_{2}=$ $50 \mathrm{ppmv}$ (not shown). The simulations are considered to have reached equilibrium if the annually averaged global mean net radiative flux at the top of atmosphere is smaller than $0.5 \mathrm{~W} \mathrm{~m}^{-2}$. For all runs shown in Fig. 1, this value is smaller than $0.25 \mathrm{~W} \mathrm{~m}^{-2}$ when averaged over the last 100 years of the simulation. In such a state, the volume-mean temperature of the deep ocean (defined here as below $1000 \mathrm{~m}$ ) is still evolving slowly with time, at a rate slower than $0.05^{\circ} \mathrm{C}(1000 \mathrm{yr})^{-1}$ except in one case (WT; $p \mathrm{CO}_{2}=140$ ppmv; Fig. 1a) for which the rate is $0.17^{\circ} \mathrm{C}(1000 \mathrm{yr})^{-1}$. The average of the last 100 years of the respective simulations is chosen as the basis of analysis in all that follows, except for those that fall into a snowball Earth for which only the data of last year are analyzed. 

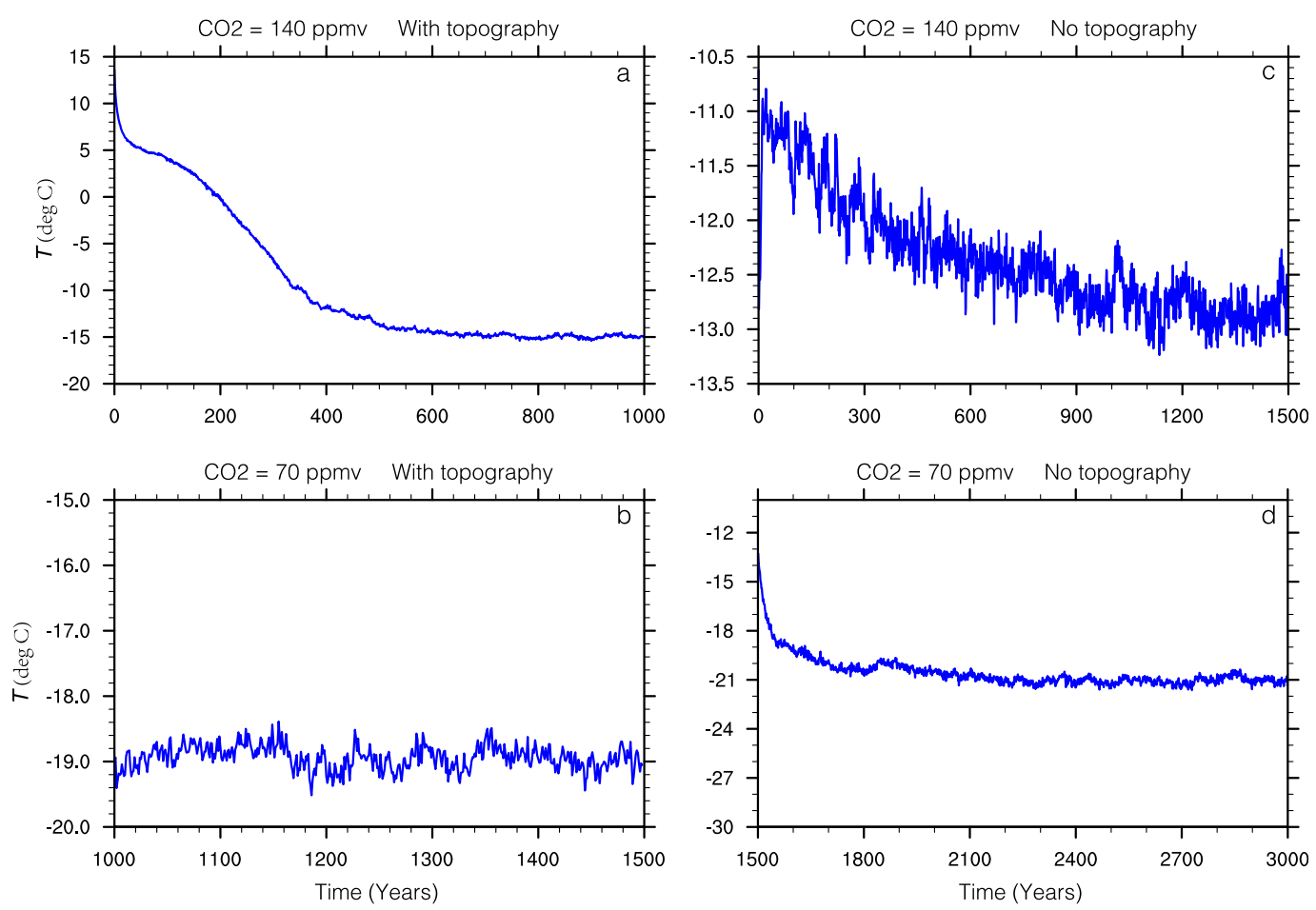

FIG. 1. Time series of globally averaged annual mean surface temperature, for (a),(b) WT and (c),(d) NT cases.

Compared to the NT cases, the land snow cover on the Eurasian continent decreases as the $p \mathrm{CO}_{2}$ is lowered to less than $140 \mathrm{ppmv}$. To understand the importance of this variation of land snow cover in snowball Earth initiation, we also perform several additional experiments for the WT case. In these experiments, $p \mathrm{CO}_{2}$ values are all lower than $140 \mathrm{ppmv}$, but snow cover in the interior of the Eurasian continent $\left(36^{\circ}-61^{\circ} \mathrm{N}, 30^{\circ}-\right.$ $112.5^{\circ} \mathrm{E}$ ) is fixed to be that for the $p \mathrm{CO}_{2}=140 \mathrm{ppmv}$ case (see Fig. 3a).

To understand the cause of the contrasting difference between our results and those of Fiorella and Poulsen (2013), we have also repeated all their relevant simulations by using only CAM3 coupled to a slab ocean of 50-m thickness. We use exactly the same setup of the model as theirs, in which the ocean heat transport is set to 0 and any adjustment to ocean heat flux is disabled (further details will be provided in section 5 below). Moreover, to decouple the influence of sea ice dynamics and that of atmospheric and oceanic heat transport, we have also carried out additional simulations (Table 2) with the fully coupled CCSM3 for both the WT and NT cases but with the sea ice dynamics disabled. If these simulations produce qualitatively similar results to the CAM3 results, it then proves that the sea ice dynamics plays a critical role in the difference between the CCSM3 results presented here and the CAM3 results in Fiorella and Poulsen (2013).

In what follows, the global mean surface temperature and the sea ice fraction are all annual means, and the latter is calculated as the ratio of total global sea ice area to ocean area.

\section{Results and discussion based upon the use of the fully coupled model CCSM3}

\section{a. Climate at $\mathrm{pCO}_{2}=140 \mathrm{ppmv}$}

With $p \mathrm{CO}_{2}$ equal to $140 \mathrm{ppmv}$, the global mean surface temperatures for the WT and NT cases are $-14.9^{\circ}$ and $-12.8^{\circ} \mathrm{C}$, and the sea ice fractions are $47.4 \%$ and $44.8 \%$, respectively, in the fully coupled model. That is, the NT case is warmer than the WT case. Moreover, the

TABLE 2. Summary of CCSM3 simulations with sea ice dynamics eliminated.

\begin{tabular}{lccccc}
\hline \hline & \multicolumn{3}{c}{ With topography $(\mathrm{WT})$} & \multicolumn{2}{c}{ No topography (NT) } \\
\hline$p \mathrm{CO}_{2}$ (ppmv) & 70 & 35 & 26 & 70 & 35 \\
Global surface temperature $\left({ }^{\circ} \mathrm{C}\right)$ & -24.9 & -28.6 & -52.0 & -23.8 & -27.0 \\
Sea ice fraction $(\%)$ & 56.1 & 60.3 & 100 & 54.1 & -55.0 \\
\hline
\end{tabular}


topographic variations in the WT case have a larger impact on the climate of the Northern Hemisphere than that of the Southern Hemisphere, as can be seen more clearly from the position of sea ice edges in each hemisphere. If the location of the sea ice edge is defined as the latitude at which the annual mean sea ice fraction in the grid cell is $50 \%$, the zonal mean sea ice edge is at $33.3^{\circ} \mathrm{S}$ in the Southern Hemisphere while it reaches $26.5^{\circ} \mathrm{N}$ in the Northern Hemisphere in the WT case (Table 1). This may be unsurprising because snow is accumulating on relatively high-elevation land surface and there are extensive high grounds near $30^{\circ} \mathrm{N}$ in the WT case (Fig. 2). On these high grounds, perennial snow can exist to the latitude of $\sim 25^{\circ} \mathrm{N}$, whereas it may exist to only $\sim 35^{\circ} \mathrm{N}$ in the NT case (Fig. 3). This increases the surface albedo over the high-topography regions in the WT case by as much as 0.45 (see the blue bands on the Eurasian continent in Fig. 4c) and consequently cools the climate. The sea ice in the WT case expands more toward the equator than in the NT case (Figs. 5a and 5d), which cools the WT climate further due to the action of a positive albedo feedback. This can be seen from the fact that the difference in surface albedo due to the different extents of land snow and sea ice does affect the planetary albedo (cf. Figs. $4 \mathrm{f}$ and 4c).

\section{b. Climate at $\mathrm{pCO}_{2}=70 \mathrm{ppmv}$}

When $p \mathrm{CO}_{2}$ is reduced by half to $70 \mathrm{ppmv}$, the global mean surface temperature of the WT case decreases by

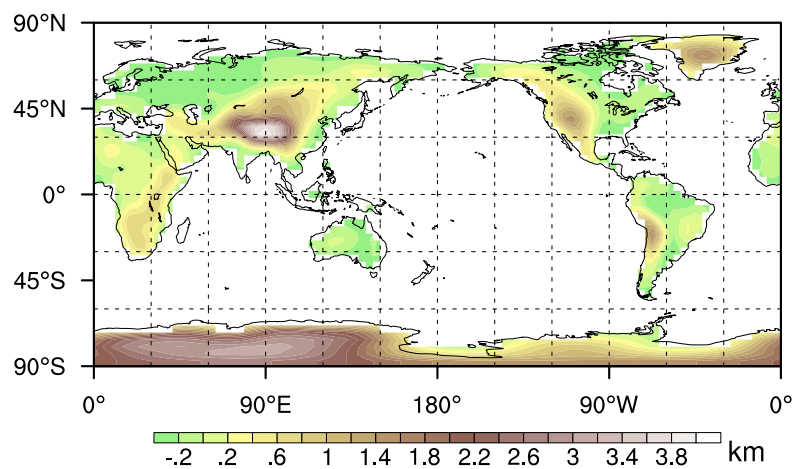

FIG. 2. Difference in surface elevation between the WT and NT cases.

$4.1^{\circ} \mathrm{C}$ but that of the NT case decreases by $8.3^{\circ} \mathrm{C}$, indicating that the NT climate is twice as sensitive to the $p \mathrm{CO}_{2}$ change as is the WT climate. Such counterintuitive results are found to be associated with an unexpected change of snow cover in the WT case. When the $p \mathrm{CO}_{2}$ is reduced and climate becomes colder, the center of the Eurasian continent transitions from snow covered to snow free in the WT case, whereas this does not happen in the NT case (Fig. 3). In the WT case, the area of snow-free land (defined here as the area in which annual-mean snow depth is $<1 \mathrm{~cm}$ ) on the Eurasian continent is only $\sim 3.2 \times 10^{6} \mathrm{~km}^{2}$ when $p \mathrm{CO}_{2}$ is $140 \mathrm{ppmv}$ (Fig. 3a) but increases dramatically to $\sim 21.0 \times 10^{6} \mathrm{~km}^{2}$ when $p \mathrm{CO}_{2}$ is reduced to $70 \mathrm{ppmv}$ (Fig. 3b). This
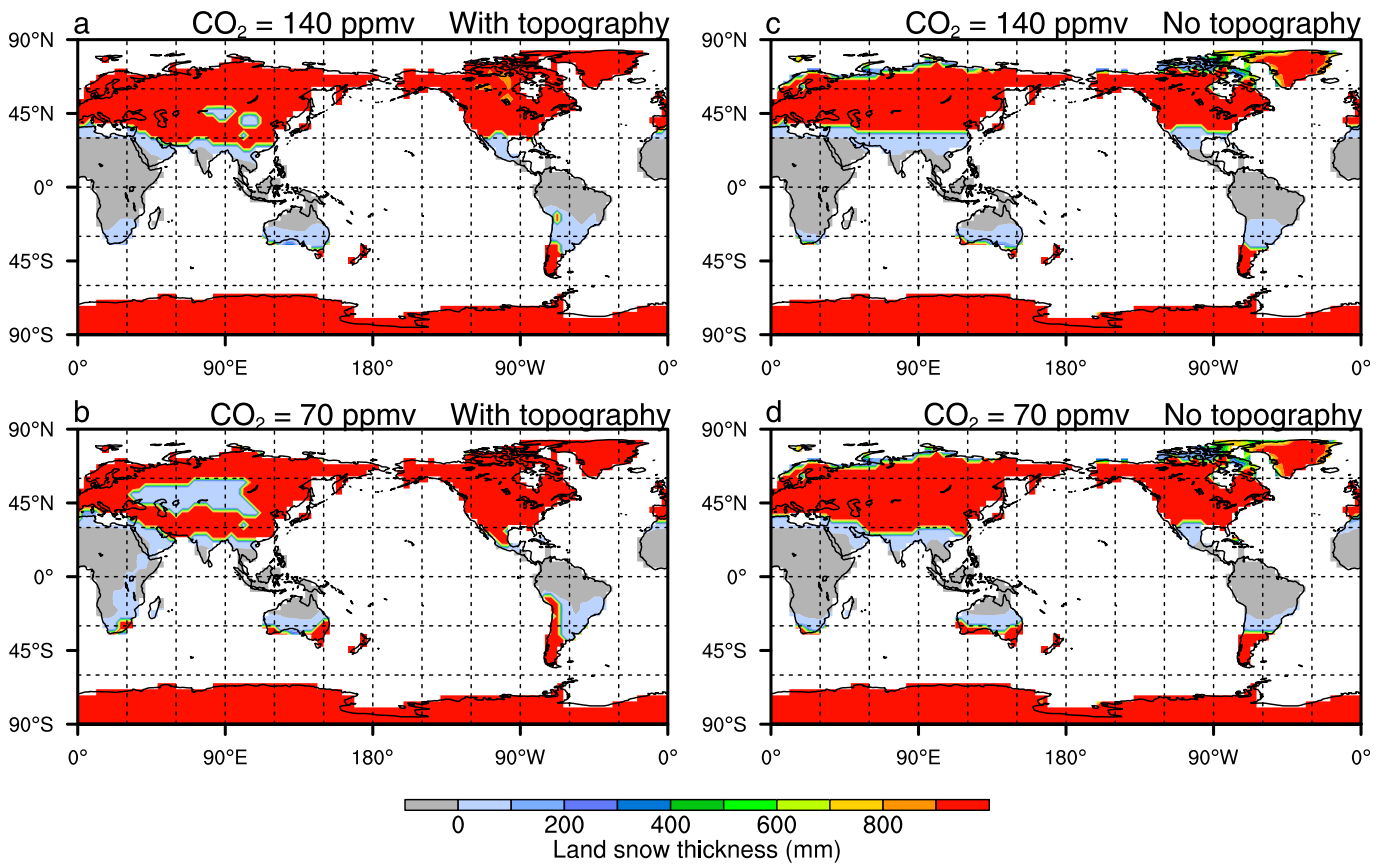

FIG. 3. (a)-(d) Annual mean snow thickness (colors) on land. Red color indicates where snow is thick and perennial. The snow thickness over the central region of the Eurasian continent in (a) and (b) is less than $10 \mathrm{~mm}$, most of which is only present during the boreal winter. 

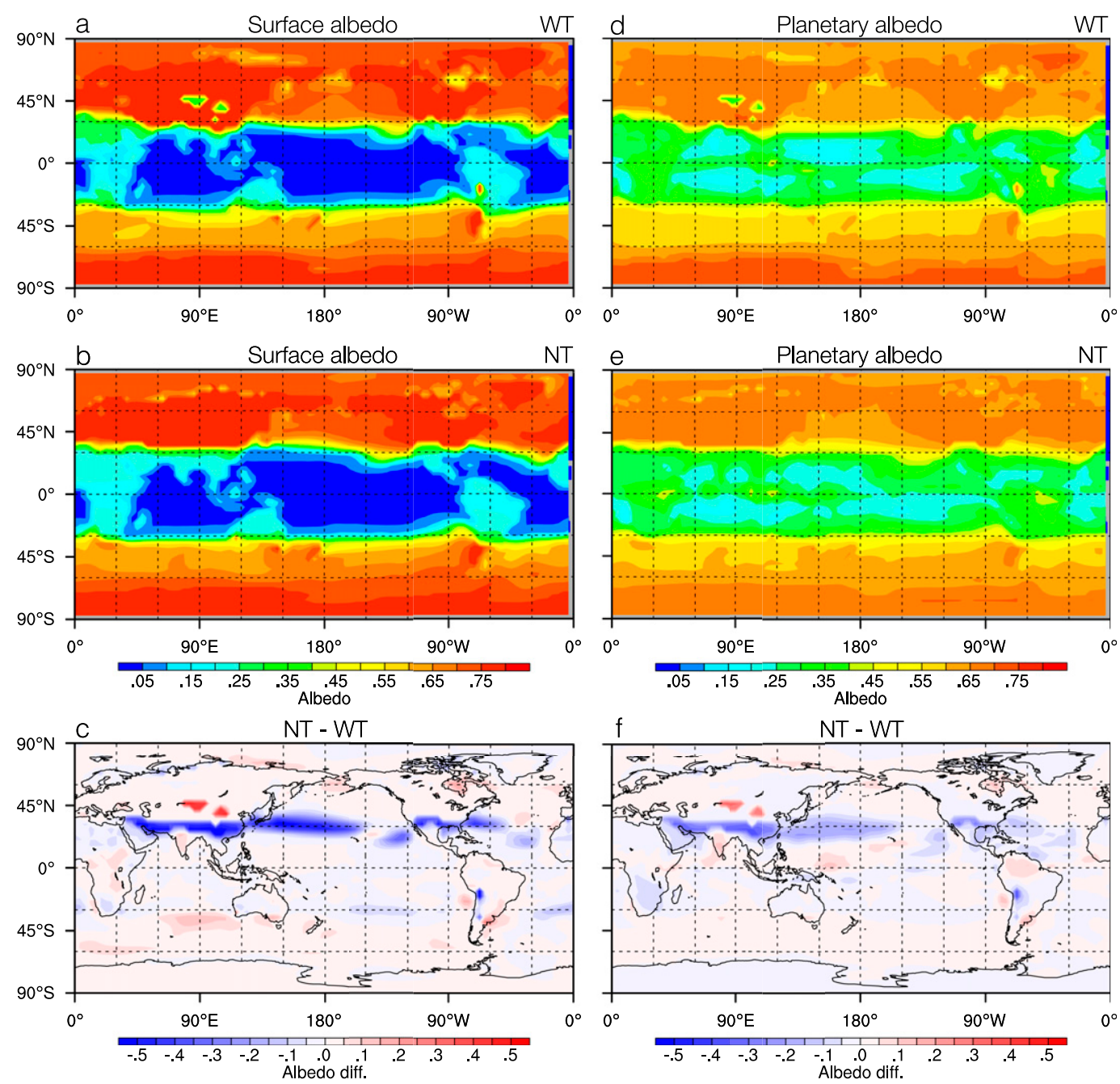

FIG. 4. Annual-mean (left) surface albedo and (right) planetary albedo for both the (a),(d) WT and the (b), (e) NT case, and (c),(f) the differences between NT and WT cases $\left(p \mathrm{CO}_{2}=140 \mathrm{ppmv}\right.$ for both cases).

reduction of snow area in the midlatitude region compensates for a large part of the expansion of the area covered by snow on land and sea ice in the ocean in the low-latitude region, in terms of the effect on surface or planetary albedos (Fig. 6; also see global mean values in Table 1). The change of snow cover in the continental interior therefore constitutes a negative feedback in the WT case when $p \mathrm{CO}_{2}$ changed. This negative feedback starts to operate only when the climate is cold enough and atmospheric water vapor is low, so that evaporation is higher than precipitation in the continental interior (see more discussion in section 3c). Apparently, the feedback also functions when $p \mathrm{CO}_{2}=140 \mathrm{ppmv}$, at which point a small area of bare land has already appeared in the middle of the Eurasian continent (Fig. 3a).

In contrast, the snow cover in the interior of Eurasian continent does not diminish at all in the NT case when $p \mathrm{CO}_{2}$ is decreased from 140 to $70 \mathrm{ppmv}$ (Fig. 3). Both the snow cover and sea ice edge march forward toward the equator (Fig. 5), causing a significant increase of the surface and planetary albedo in the low-latitude region (Figs. 6c and 6d). The global mean planetary albedo becomes 0.488 for the NT case, which is higher than 0.479 for the WT case, and therefore the NT climate becomes colder than the WT climate.

\section{c. Reduced water vapor transport to the Eurasian interior}

The water vapor content in the atmosphere decreases as the climate cools (Table 1), and precipitation also decreases globally (not shown). The water vapor over the interior of the Eurasian continent originates mostly from the tropical oceanic region to the southwest in a near-snowball climate (arrows in Fig. 7). The water 

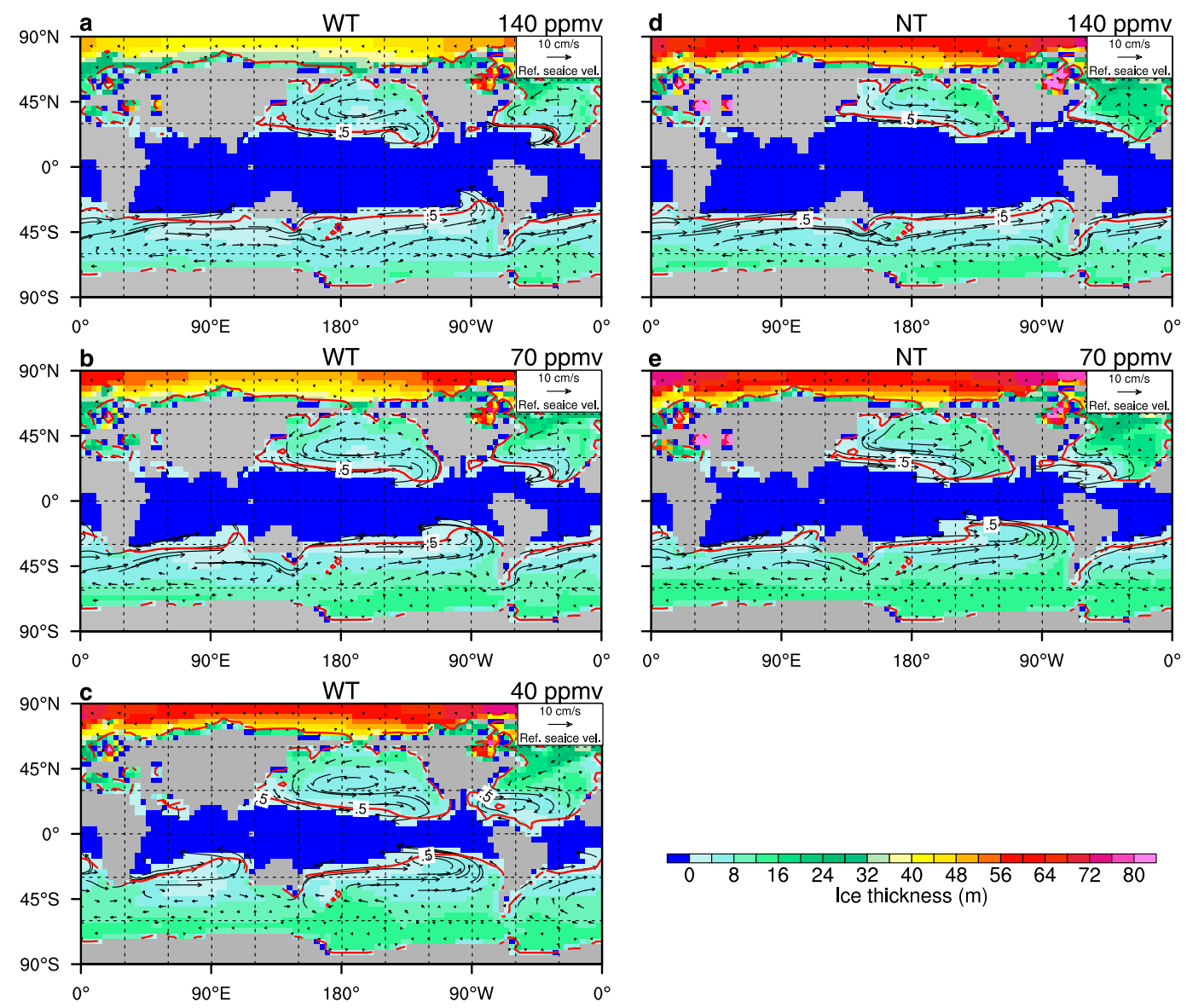

FIG. 5. Annual-mean sea ice thickness for the (a)-(c) WT case and (d),(e) NT case. The $p \mathrm{CO}_{2}$ values are indicated in the top-right corner of each panel.

vapor content in the atmosphere gradually decreases along its path from the source region to the interior of the Eurasian continent due to precipitation en route. When there is topography near the southwest border of the continent, however, the water vapor is reduced rapidly by enhanced precipitation over the region of high topography (indicated by the enhanced convergence of water vapor around the border, shown in red in Figs. $7 \mathrm{a}$ and $7 \mathrm{~b}$ ). On the lee side of the high topography, the rain shadow effect (Galewsky 2009) due to warming of the descending air is obvious; the water vapor transport diverges there (blue color in Figs. $7 \mathrm{a}$ and $7 \mathrm{~b}$ ), meaning that net evaporation occurs there annually. When the $p \mathrm{CO}_{2}$ is lowered from 140 to $70 \mathrm{ppmv}$, the water vapor transport from the southwest to the center of the Eurasian continent is greatly reduced in terms of both absolute magnitude (the change of vectors shown in Fig. 7c) and the convergence (the blue color in Fig. 7c). Although this happens also for the NT case (Figs. 7f), only for the WT case are the precipitation rates (all of which consist of snow) around the center of the Eurasian continent reduced so much (Figs. 8a and 8b) that the evaporation during the warm months is able to eliminate all of the snow by sublimation (Fig. 8c). The high topography, such as the Iranian Plateau, the Anatolian Plateau, and Tibetan Plateau (Fig. 2), therefore acts as a barrier to the transport of water vapor from the source region toward the continental interior. In the NT case, the water vapor flux from the oceans to the continental interior also decreases with decreasing $p \mathrm{CO}_{2}$, but not to the extent that would cause net evaporation (Figs. 7e and 8).

\section{d. Snowball Earth initiation}

The NT case enters a snowball Earth when $p \mathrm{CO}_{2}$ is decreased slightly from 70 to $60 \mathrm{ppmv}$, whereas for the WT case, a snowball Earth does not form until $p \mathrm{CO}_{2}$ is decreased to 35 ppmv (i.e., another halving of $\mathrm{CO}_{2}$ ) (Table 1). Therefore, the presence of topography may make the initiation of a snowball Earth more difficult. Moreover, sea ice can reach much lower latitude in the WT case than in the NT case without causing the climate to descend into a snowball state (cf. Figs. 5c and 5e). The 

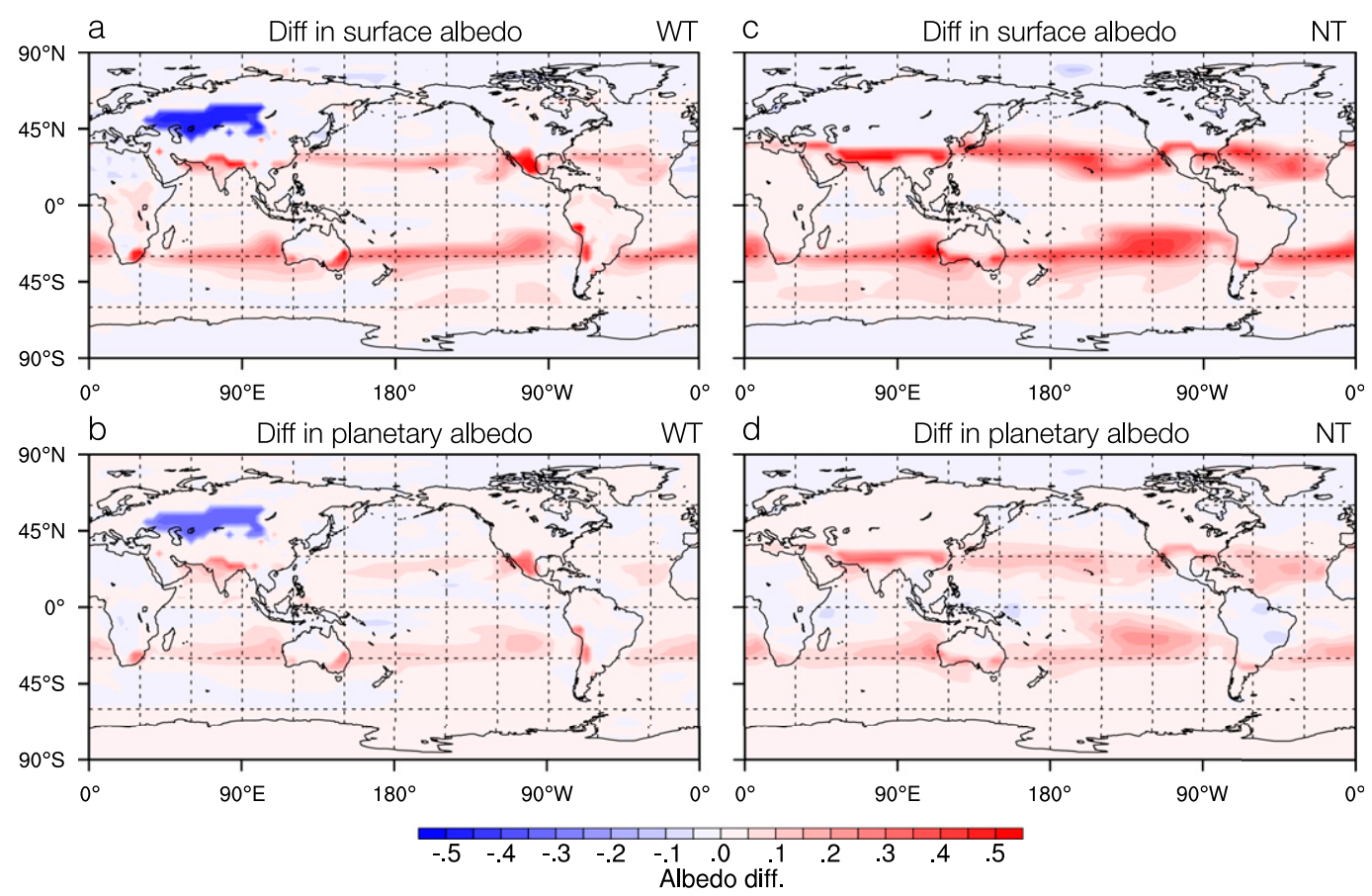

FIG. 6. Change of (a),(c) surface and (b),(d) planetary albedo when $p \mathrm{CO}_{2}$ is reduced from 140 to 70 ppmv, for the (left) WT and (right) NT cases.

zonal mean sea ice edge can reach $18^{\circ}$ in the WT case (Fig. 5c) but only $24^{\circ}$ in the NT case (Fig. 5e).

It is natural to attribute the difference between the results for the WT and NT cases to the negative feedback associated with snow cover reduction in the interior of the Eurasian continent in the WT case. However, it is uncertain whether some other processes may also be playing significant roles (e.g., clouds and atmospheric and oceanic heat transports), which could all be different between the WT and NT cases. To show that these (and other unknown) processes are not playing any important role, we perform several additional experiments for the WT case in which the snow cover in the interior of the Eurasian continent is fixed (see section 2). In this way the negative feedback due to the change of land snow area is turned off. It is found that Earth enters a hard snowball Earth when $p \mathrm{CO}_{2}=60 \mathrm{ppmv}$, rather than $35 \mathrm{ppmv}$ when the feedback was on. In the meantime, the maximum sea ice extent is reduced from $64 \%$ to $59 \%$. These are all similar to those for the NT case (Table 1). Therefore, the feedback due to the change of snow area on Eurasian continent is indeed the dominant cause of the difference in snowball initiation and maximum sea ice extent between the WT case and the NT case.

These results explain in large part why the lowest latitude of the (zonal mean) sea ice edge was found to be $\sim 25^{\circ}$ in Liu et al. (2013), but it could reach $\sim 15^{\circ}$ in Yang et al. (2012a,b); the continents were flat in the simulations of Liu et al. (2013) whereas the present-day topography was employed in Yang et al. (2012a,b).

\section{Results for the atmosphere-only model CAM3}

Fiorella and Poulsen (2013) also found that snow cover decreases on the midlatitude continents with decreasing solar insolation in the WT case, causing the planetary albedo to be lower over the same regions. However, they concluded that the WT case enters a snowball state more easily than the NT case, contrary to what we have found here. To understand the cause of this difference, we have repeated all the relevant simulations in Fiorella and Poulsen (2013) using CAM3 coupled to a slab ocean of 50-m thickness. In these simulations, $p \mathrm{CO}_{2}$ is fixed at $280 \mathrm{ppmv}$, but the total solar insolation (TSI) is reduced in order to force the climate into a hard snowball state. The major difference between these simulations and CCSM3 simulations in section 3 is that the dynamics of the ocean and sea ice are neglected in these CAM3 simulations.

When TSI is reduced to $90 \% \mathrm{TSI}_{0}$, snow cover over both the Eurasian and North American continents is much reduced in the WT case compared to that in the NT case in the CAM3 simulations (Fig. 9), even more significantly than in the CCSM3 simulations (Fig. 3b). This reduced snow cover does lead to warming of the exposed land surface. The warming is more than $10^{\circ} \mathrm{C}$, and is extended to the whole latitudinal band between 

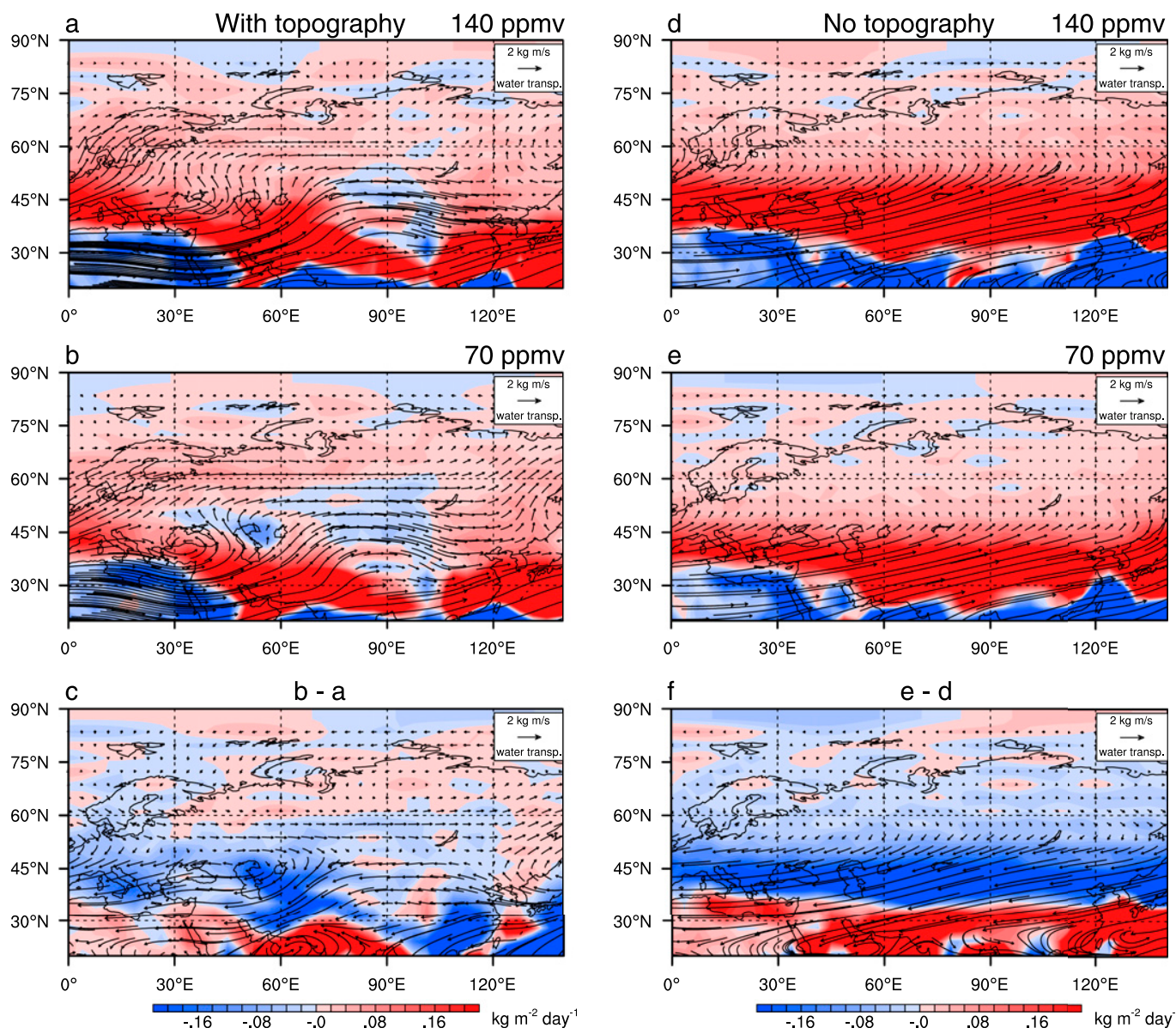

FIG. 7. Vertically integrated water vapor flux (vectors) and convergence of the flux (filled color) over Eurasia, shown (a),(b) with surface topography and (d),(e) without surface topographic variations. The $p \mathrm{CO}_{2}$ values of the corresponding simulations are indicated on each panel. Also shown are (c) the difference between (b) and (a), and (f) the difference between (e) and (d).

$35^{\circ}$ and $70^{\circ} \mathrm{N}$ (Fig. 10). Such a significant warming is partially due to the fact that the North American continent also becomes snow free in addition to the Eurasian continent. Note that the global mean surface temperature in the CAM3 runs can reach much lower values $\left(\sim-33^{\circ} \mathrm{C}\right)$ than in the $\mathrm{CCSM} 3$ runs $\left(\sim-21^{\circ} \mathrm{C}\right.$; see Table 1) without entering a snowball Earth state, probably due to lack of sea ice dynamics (Voigt and Abbot 2012). Therefore, the global mean water vapor content in the CAM3 runs is only $1.5 \mathrm{~kg} \mathrm{~m}^{-2}$, much lower than can be reached in the CCSM3 runs (Table 1). Such low water vapor content helps create a large snowfree region in North America. The warming over the continents induces snow sublimation over sea ice over the same latitudinal bands (not shown). Because sea ice has a lower albedo than snow in CAM3, this causes the temperature over sea ice in this region to increase (Fig. 10b).

The warming induced by the expansion of the snowfree area in the WT case does not, however, help resist the occurrence of a snowball. The WT case enters a hard snowball when TSI is reduced to $89 \% \mathrm{TSI}_{0}$, while the NT case enters a hard snowball when TSI is reduced to $87 \%$ $\mathrm{TSI}_{0}$. These results are entirely consistent with those obtained by Fiorella and Poulsen (2013). These authors speculated that the easier initiation of a snowball Earth in the WT case was because the meridional temperature gradient in the WT case was much smaller than that in the NT case (Fig. 11b). A smaller meridional temperature gradient allows greater expansion of sea ice when solar insolation or greenhouse gas concentration is reduced.

\section{Detailed analyses of the cause of the differences between CAM3 and CCSM3}

\section{a. Different model configurations between CAM3 and CCSM3}

Besides the difference in model complexity between CAM3 and CCSM3, there are two other differences in 

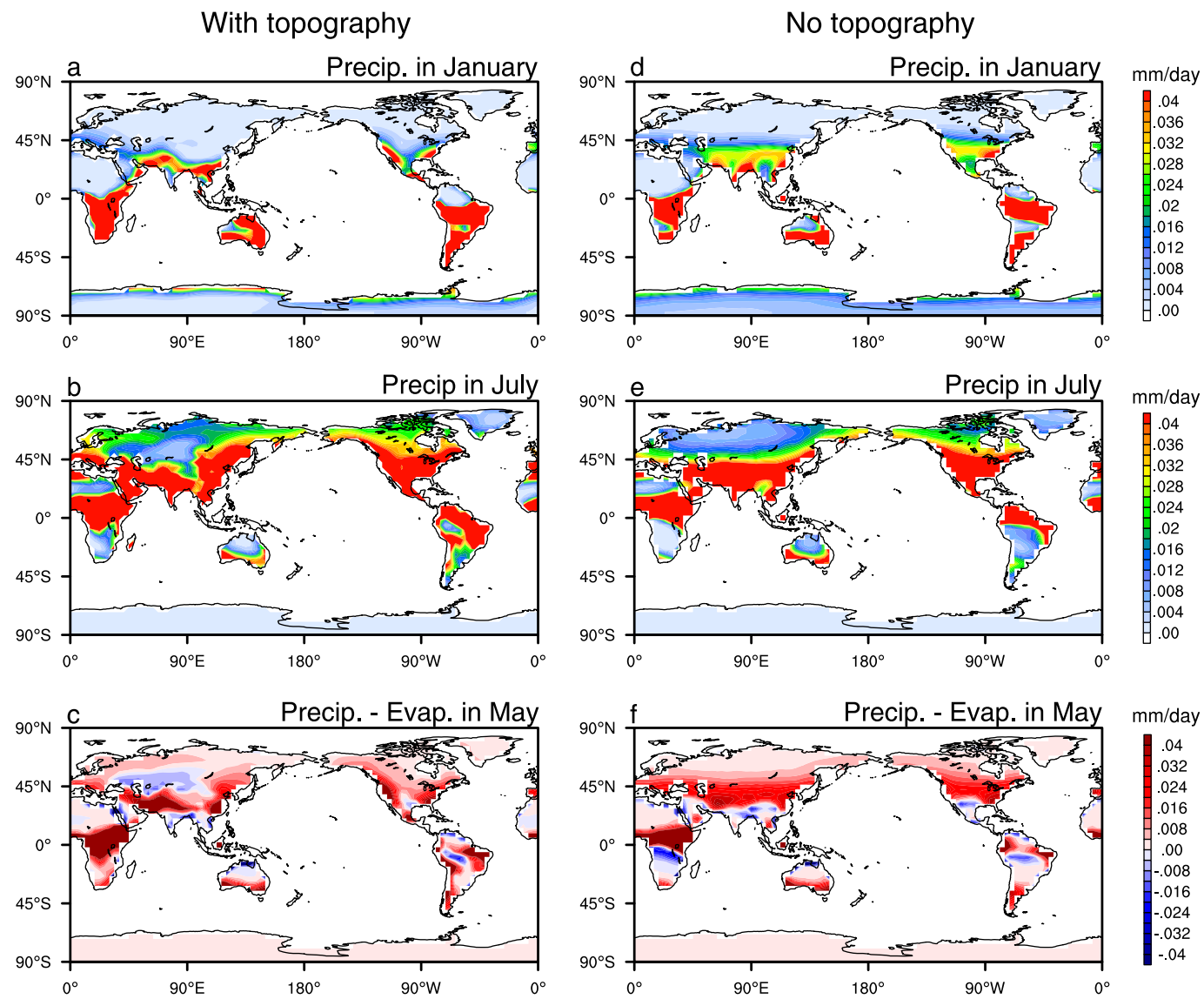

FIG. 8. Precipitation in (top) January and (middle) July, and (bottom) precipitation minus evaporation in May, for continental configurations (a)-(c) with and (d)-(f) without topography. The results are obtained by CCSM3 simulations with $p \mathrm{CO}_{2}=70 \mathrm{ppmv}$. The precipitation minus evaporation in May is chosen because it is the most negative in the Northern Hemisphere throughout the year.

the configurations of the CAM3 and CCSM3 simulations: the orbital configuration and the way in which climate is cooled. In the CAM3 simulations of Fiorella and Poulsen (2013), the obliquity was $23.5^{\circ}$, close to that of present-day value, but the orbit had zero eccentricity and the vernal equinox was at perihelion (which does not matter for a zero eccentricity); moreover, the climate was cooled by reducing the solar constant. In our
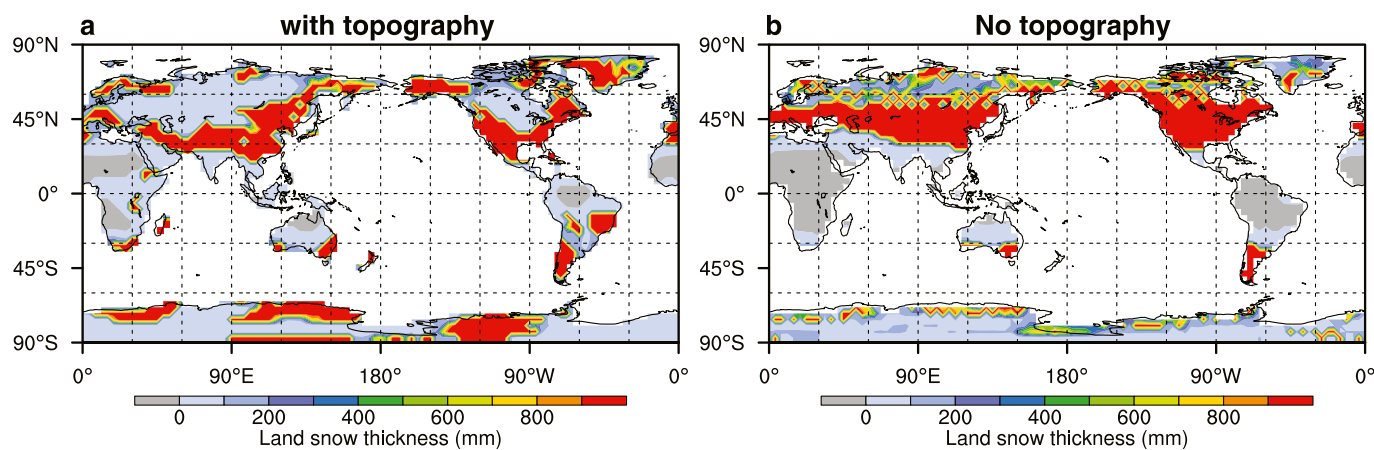

FIG. 9. Annual-mean snow depth on land obtained with CAM3 coupled with a slab ocean, as in Fiorella and Poulsen (2013), where (a) the present-day topography is kept and (b) the topography is removed, and the elevation of all land surface is $100 \mathrm{~m}$. TSI is $90 \% \mathrm{TSI}_{0}$ and $p \mathrm{CO}_{2}$ is $280 \mathrm{ppmv}$ for both runs. Both runs were carried out for 500 years and the average of the last 50 years is shown. 

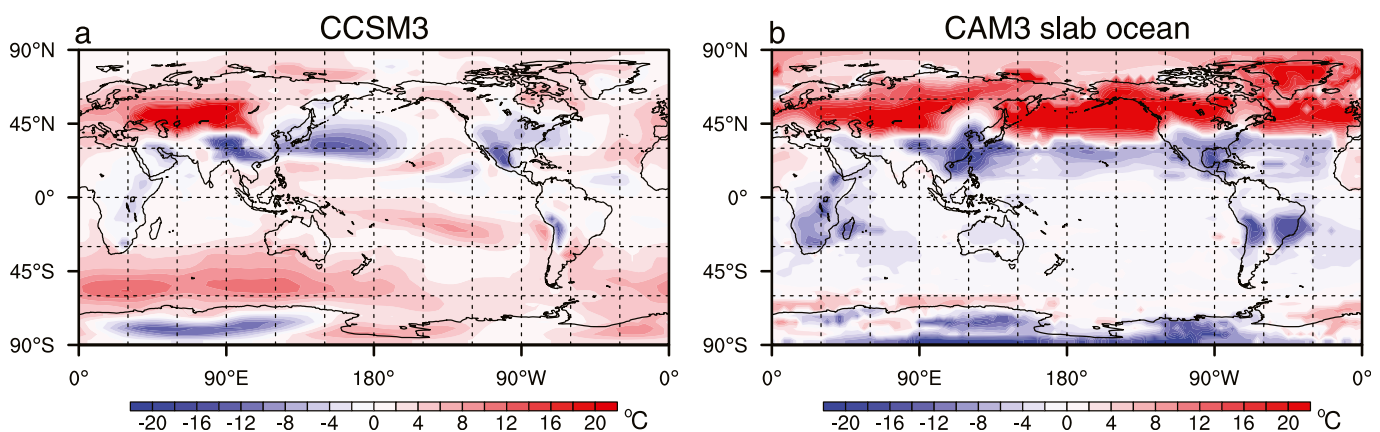

FIG. 10. Difference in surface temperature between WT and NT cases obtained by (a) CCSM3 and (b) CAM3. For the CCSM3 simulations, $p \mathrm{CO}_{2}=70 \mathrm{ppmv}$ and solar constant is $94 \%$ of present-day value; for CAM3 simulations, $p \mathrm{CO}_{2}=280 \mathrm{ppmv}$ and TSI is $90 \% \mathrm{TSI}_{0}$ (Fiorella and Poulsen 2013).

CCSM3 simulations herein, however, the orbit is the same as present day (year 1990), for which obliquity is $23.44^{\circ}$, eccentricity is 0.0167 , and the vernal equinox is about $103^{\circ}$ from the perihelion, and the climate is cooled by reducing $p \mathrm{CO}_{2}$. To rule out the influence of these differences as the cause of the difference between CAM3 and CCSM3 results, two sets of additional experiments were carried out using CAM3. In one set, the orbital parameters are set to be the same as those in CCSM3; in the other, the solar constant is fixed at $94 \%$ of the present-day value, while $p \mathrm{CO}_{2}$ is reduced to initiate a snowball Earth. It is found that in both sets of experiments, the WT case enters a hard snowball Earth more easily than the NT case; $89 \%$ in the WT case versus $88 \%$ in the NT case, or 6 ppmv in the WT case versus 3 ppmv in the NT case. Therefore, these two factors are not the cause of the distinct difference between the results of CAM3 and CCSM3.

The documentation of the models asserts that the snow depth on sea ice in CCSM3 is capped at $0.5 \mathrm{~m}$, and may be different in CAM3 (not described). If that is true, it may be a further minor difference between CAM3 and CCSM3 that may contribute to the difference in the results between the two models. From the model output, however, we do not see any capping on this variable in either of the models. Therefore, this model difference may not actually exist.

\section{b. Meridional temperature gradient}

Given the results of the fully coupled CCSM3 simulations we have obtained, we will argue that the speculation of Fiorella and Poulsen (2013) concerning why their simulation with continental topography was found to be more susceptible to entering a snowball state is likely incorrect. To this end Fig. 11a shows the meridional temperature gradient of the CCSM3 simulations with $p \mathrm{CO}_{2}=70 \mathrm{ppmv}$ for both the WT and NT cases. It will be seen that the temperature gradient for the WT case is in fact smaller than that in the NT case (between $35^{\circ}$ and $50^{\circ} \mathrm{N}$ ), similar to that in CAM3, but the WT case is found to be more difficult to force into a snowball Earth as described in section 3d. Moreover, the sea
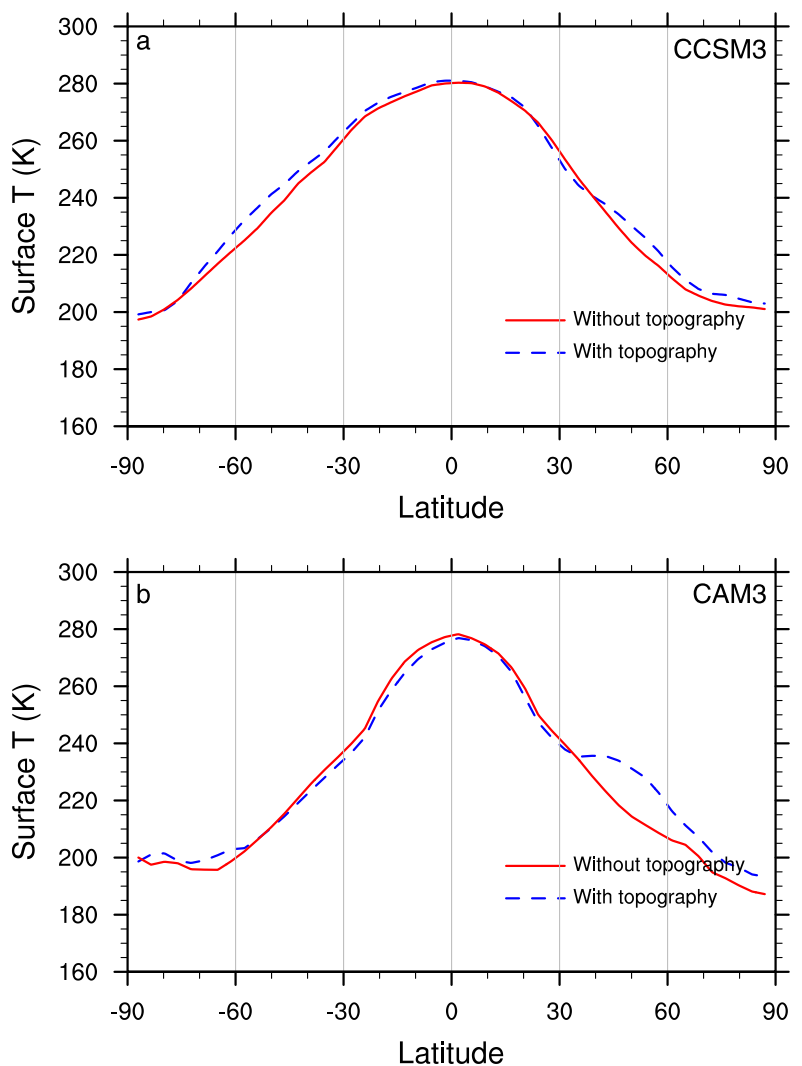

FIG. 11. Zonal mean surface temperature for runs with and without continental topography obtained by (a) CCSM3 simulations with $p \mathrm{CO}_{2}=70 \mathrm{ppmv}$, TSI $=94 \% \mathrm{TSI}_{0}$ and (b) CAM3 simulations with $p \mathrm{CO}_{2}=280 \mathrm{ppmv}$, TSI $=90 \% \mathrm{TSI}_{0}$. The general equator to pole temperature gradient is similar for the two runs, in contrast to what was obtained by Fiorella and Poulsen (2013) using CAM3 coupled with a slab ocean. Locally, the gradient is relatively small between $35^{\circ}$ and $45^{\circ} \mathrm{N}$ for the run with continental topography. 

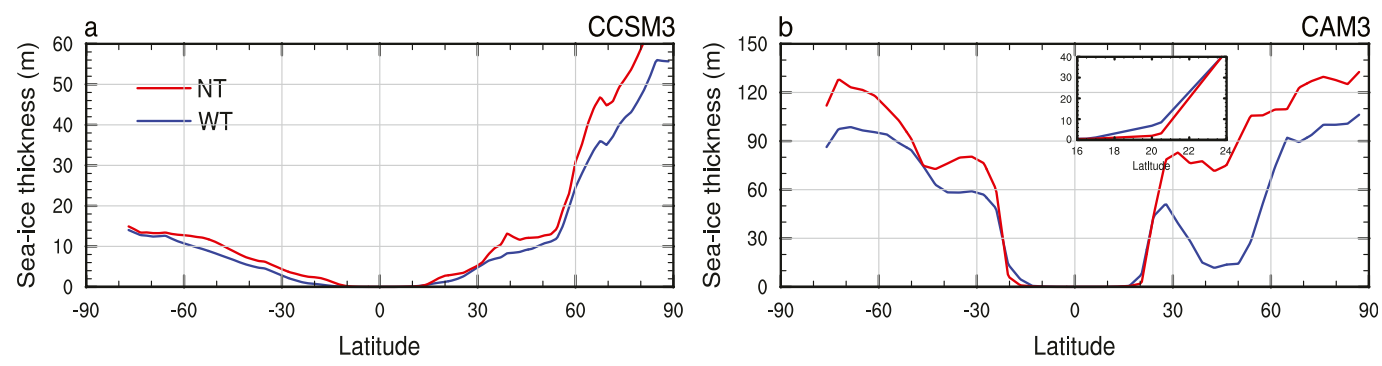

FIG. 12. Zonal mean sea ice thickness obtained by (a) CCSM3 and (b) CAM3, respectively. For the CCSM3 simulations, $p \mathrm{CO}_{2}=70 \mathrm{ppmv}$ and the solar constant is $94 \%$ of the present-day value; for CAM3 simulations, $p \mathrm{CO}_{2}=280 \mathrm{ppmv}$ and the solar constant is $90 \%$ of the present-day value (Fiorella and Poulsen 2013). The ice thickness near the ice edge in the Northern Hemisphere is zoomed-in in (b).

ice edges have entered the region equatorward of $30^{\circ}$ latitude (Fig. 12), where the meridional temperature gradient in the WT case is actually larger than that in the NT case in both CCSM3 and CAM3 simulations (Fig. 11). The zonal mean surface temperature averaged over only the oceanic (and sea ice) area is very similar to that shown in Fig. 11 (not shown). If the meridional temperature gradient were playing a critical role, this should have made the initiation of a snowball Earth more difficult in the WT case in CAM3, the opposite to the result found in section 4. Therefore, the difference in meridional temperature gradient between the WT and NT cases is not the fundamental reason why the WT case enters a snowball Earth more easily than the NT case in CAM3. The actual reason, as will be described in what follows, is found to be related to the manner in which tropical sea ice grows in CAM3.

\section{c. Tropical sea ice growth in CCSM3 versus CAM3}

The most critical difference between CCSM3 and CAM3 that is relevant to snowball Earth initiation concerns the manner in which sea ice grows in the tropical region. For CAM3, despite much thinner sea ice in the mid- to high-latitude region in the WT case than in the NT case, the sea ice in the tropical region is significantly thicker in the former than in the latter (Fig. 12b). This is in contrast to the sea ice thickness distribution obtained in CCSM3 (Fig. 12a). How this happens is the key to understanding why the WT case enters a snowball Earth state more easily than the NT case in CAM3.

Because of high surface topography, snow accumulates on low-latitude land surfaces more easily in the WT case than in the NT case, in both the CCSM3 and CAM3 simulations (Figs. 3 and 9). This causes the land surface temperature there to be lower in the WT case than in the NT case (e.g., $20^{\circ}-40^{\circ} \mathrm{N}$ in Fig. 10a, and the whole tropical region in Fig. 10b), even after the temperature is adjusted to the same altitude using a moist adiabatic lapse rate adjustment (except for the Tibetan Plateau). The cold temperature over land has a cooling effect over the oceans at similar latitudes, due to the near-zonal eastward wind over these latitudes (Fig. 13). For the CCSM3 simulations, cold air from high latitudes also contributes to the cooling over the west Pacific near $30^{\circ} \mathrm{N}$ (Fig. 13a). Because of this cooling, the sea ice growth over these latitudes is more significantly enhanced in the WT case than in the NT case $\left(25^{\circ}-40^{\circ} \mathrm{N}\right.$ in Fig. $14 \mathrm{~b}$, and $10^{\circ}-30^{\circ} \mathrm{N}$ in Fig. 14d). The sea ice growth shown in Figs. 14b and 14d is mostly due to basal freezing (not shown). This is the reason why tropical sea ice is thicker in the WT case than in the NT case in CAM3 (Fig. 12b), and thus why the WT case enters a snowball Earth state more easily. In contrast, the tropical sea ice is thinner in the WT case than in the NT case in CCSM3 because the thermal growth of sea ice (frazil ice formation, snow conversion, and basal congelation) is not important there.

The tropical sea ice growth in CCSM3 is primarily due to sea ice transport (cf. Figs. 14a and 14b) whereas it is exclusively due to thermal growth in CAM3 (Figs. 13c and 13d). Because the sea ice in mid- to high-latitude regions in the WT case is thinner than that in the NT case (Fig. 12a) (presumably due to the warmer land surface; Fig. 10a), less sea ice is transported to the tropical region in the former than in the latter (Fig. 14a). This is so despite the fact that more sea ice grows thermally around $30^{\circ} \mathrm{N}$ in the WT case than in the NT case (Fig. 14b). This produces a warming effect in the tropical region that is further enhanced through the action of sea ice albedo feedback, and overwhelms the direct cooling effect of high topography in the low latitudes. In CAM3, thin midlatitude sea ice does not help reduce the thickness of the tropical sea ice. The negative feedback due to exposure of the surface of the continental interior described in section 3 thus does not have a strong impact on the tropical climate 

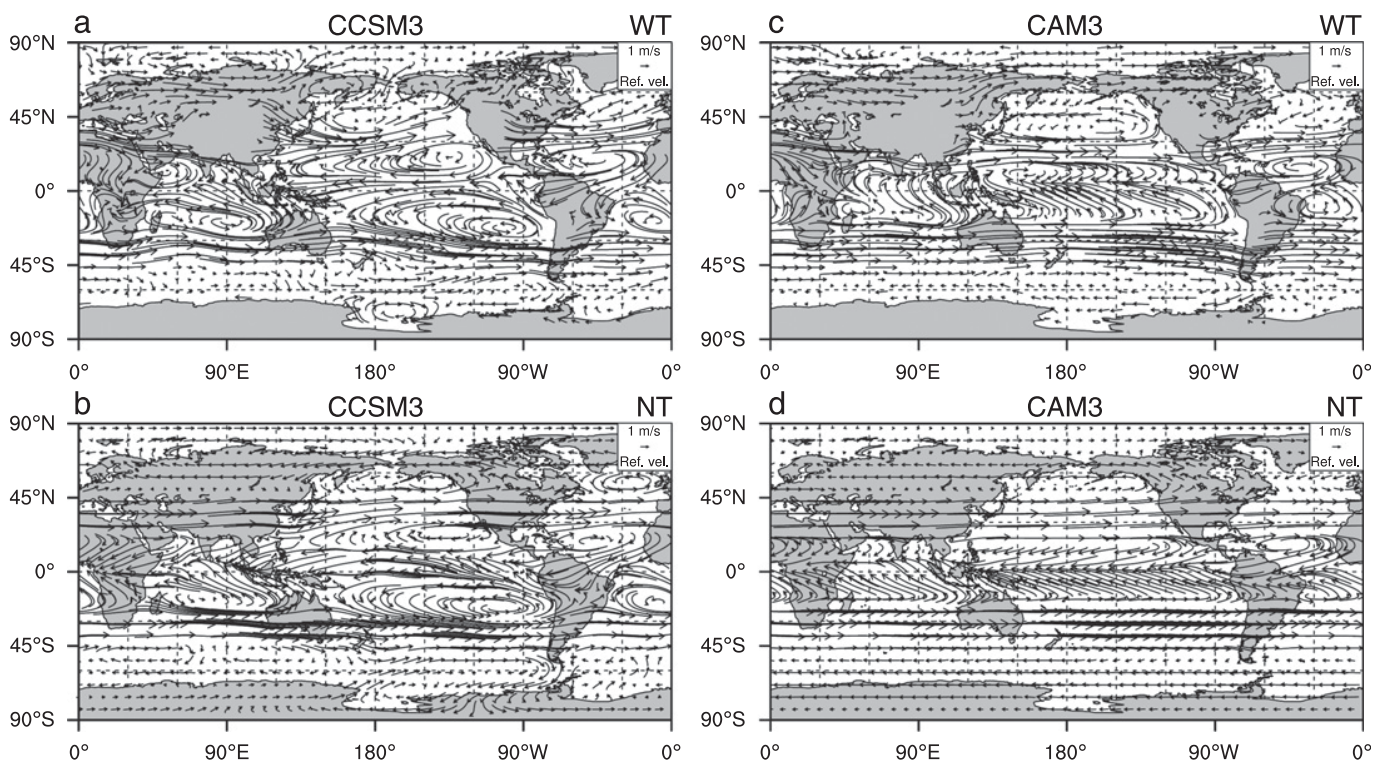

FIG. 13. Wind velocity at 850-hPa pressure level in the (a),(b) CCSM3 and (c),(d) CAM3 simulations. Topography is present in the top panels and is flat in the bottom panels. For the CCSM3 simulations, $p \mathrm{CO}_{2}=70 \mathrm{ppmv}$ and the solar constant is $94 \%$ of the present-day value; for CAM3 simulations, $p \mathrm{CO}_{2}=280 \mathrm{ppmv}$ and the solar constant is $90 \%$ of the present-day value.

in CAM3. The simplification in sea ice processes in CAM3 causes it to produce unrealistically thick tropical sea ice in the WT case, and leads directly to the incorrect conclusion concerning the influence of continental topography on snowball Earth initiation. This conclusion is further corroborated by results of additional simulations in the following section. We note that all other results presented in Fiorella and
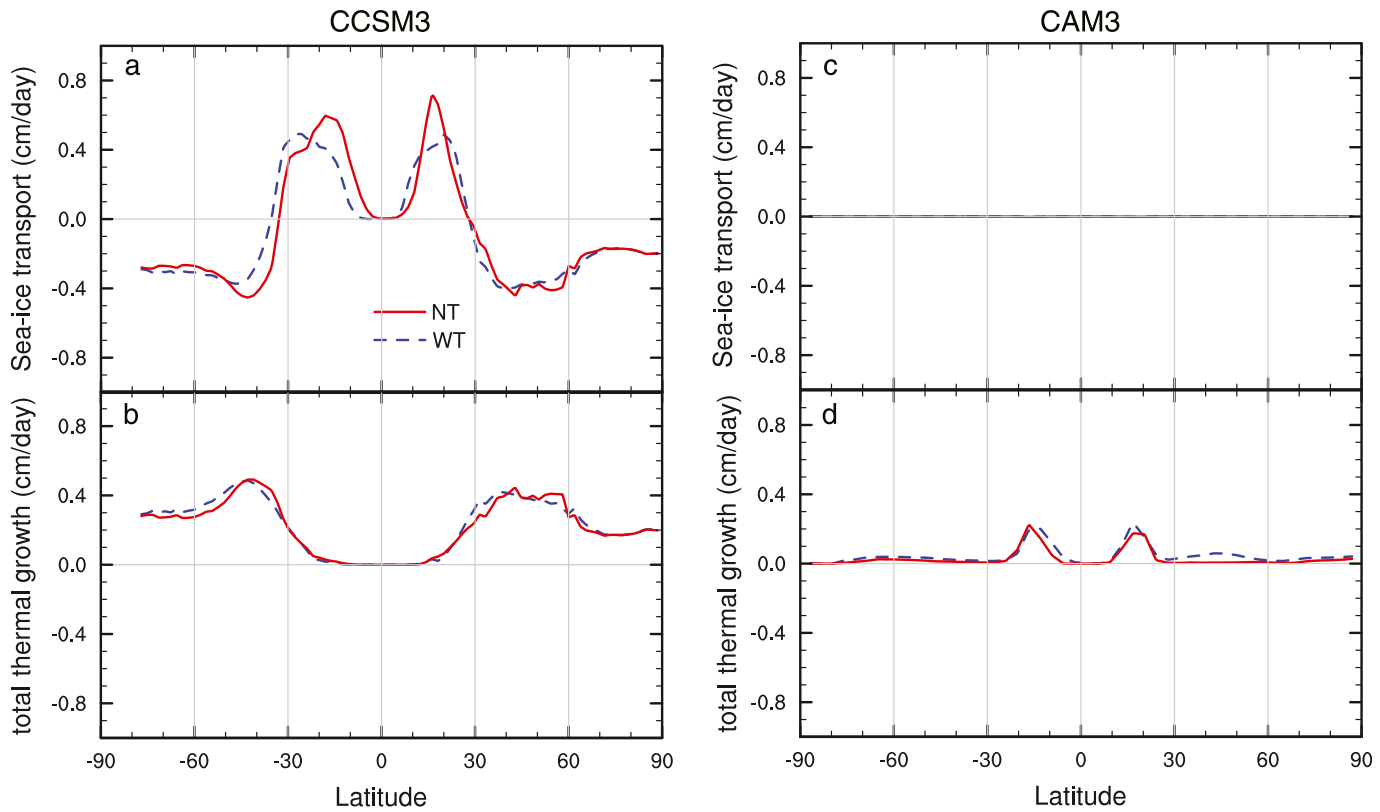

FIG. 14. Sea ice growth rate due to the (a),(c) dynamic transport and (b),(d) thermal processes (including frazil growth, snow conversion, and basal congelation, but the basal congelation contributes the most) in the (left) CCSM3 and (right) CAM3: $p \mathrm{CO}_{2}=70$ ppmv and solar constant is $94 \%$ of present-day value in the CCSM3 simulations; they are 280 ppmv and $90 \%$ in the CAM3 simulations. There is no ice dynamics in CAM3, so the values are all zero in (c). 

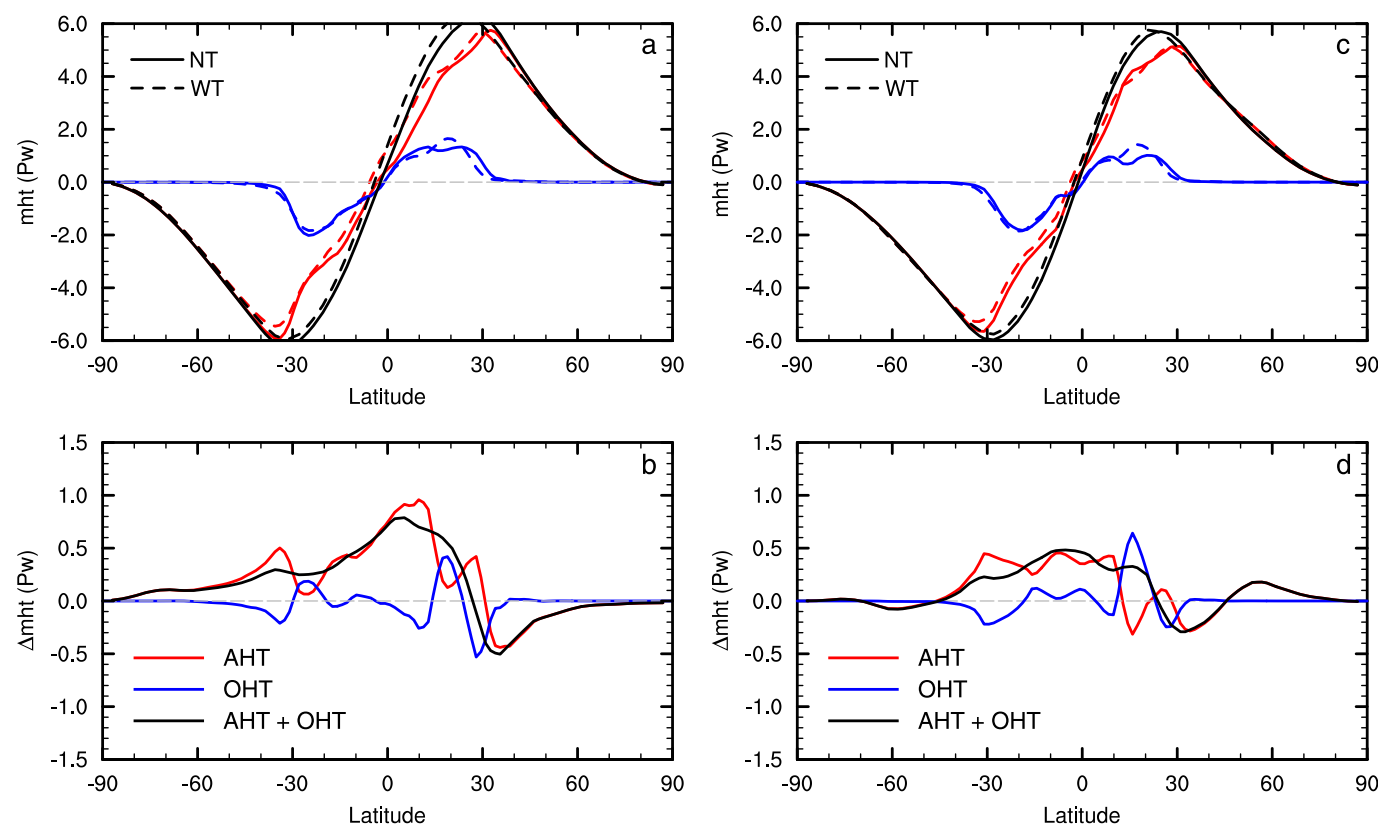

FIG. 15. (a),(c) The atmospheric (red), oceanic (blue), and total (black) meridional heat transports and (b),(d) the differences between WT and NT cases (WT - NT) from results of CCSM3 simulations. Northward transport is defined as positive; $p \mathrm{CO}_{2}=140$ ppmv for panels on the left and $70 \mathrm{ppmv}$ for the right.

Poulsen (2013) are unaffected by the analysis presented herein.

\section{d. Meridional heat transport and the sea ice dynamics}

It may be expected that the meridional heat transport may play a role in the contrasting results between CCSM3 and CAM3, especially the fact that CAM3 does not have an active ocean and thus lacks the influence of oceanic heat transport. Whether or not the topography is present, both the maximum atmospheric and oceanic heat transports decrease when $p \mathrm{CO}_{2}$ is reduced from 140 to $70 \mathrm{ppmv}$ in the CCSM3 runs (Fig. 15). The most significant difference between the WT and NT cases is probably in the mid- to high latitudes $\left(45^{\circ}-90^{\circ} \mathrm{N}\right)$, where the poleward heat transport by the atmosphere is enhanced in the WT case relative to the NT case (Fig. 15d). This should be due to the warming in the midlatitudes induced by reduction of land snow cover in the WT case. The oceanic heat transport, as well as the total heat transport, does not seem to change differently between the WT and NT cases in other regions when $p \mathrm{CO}_{2}$ is reduced. The poleward heat transport in the northern middle to high latitudes in the CAM3 runs is also larger in the WT than in the NT case (Fig. 16), similar to the CCSM3 runs. It is hard to tell from these results whether the oceanic meridional heat transport plays an important role in causing the difference between the CCSM3 and CAM3 simulations.
Additional simulations are carried out using CCSM3 but with the dynamics of sea ice eliminated entirely. It is then found that, without any other modification, the WT case becomes colder than the NT case when $p \mathrm{CO}_{2}=$ 70 ppmv (Table 2) and it enters a hard snowball Earth more easily than the NT case, a qualitatively similar result to those of the CAM3 simulations. This may prove that the oceanic heat transport is unimportant, while the sea ice dynamics are critical in causing the difference between the CCSM3 and CAM3 simulations.

The analysis above shows that sea ice dynamics are able to transmit a warming anomaly from the mid- or perhaps even higher latitudes to the low latitudes, thereby rendering its climate impact global. The warming anomaly first produces anomalously thin sea ice in the mid- or high latitudes, and then the thinned sea ice is transported to the low-latitude region and produces the warming anomaly there. This always happens as long as there are westerly winds in the midlatitudes, which drive an equatorward Ekman transport of sea ice. Or, when there is a continent in the midlatitudes, a horizontal gyre circulation of the ocean, and the existence of sea ice, this also results in an exchange of sea ice between the middle and low latitudes even if the wind is easterly in the midlatitudes. The atmosphere and ocean may also transmit the warming signal from the midlatitudes to low latitudes by transporting less heat from the tropics to the midlatitudes. However, the analyses above demonstrate that 

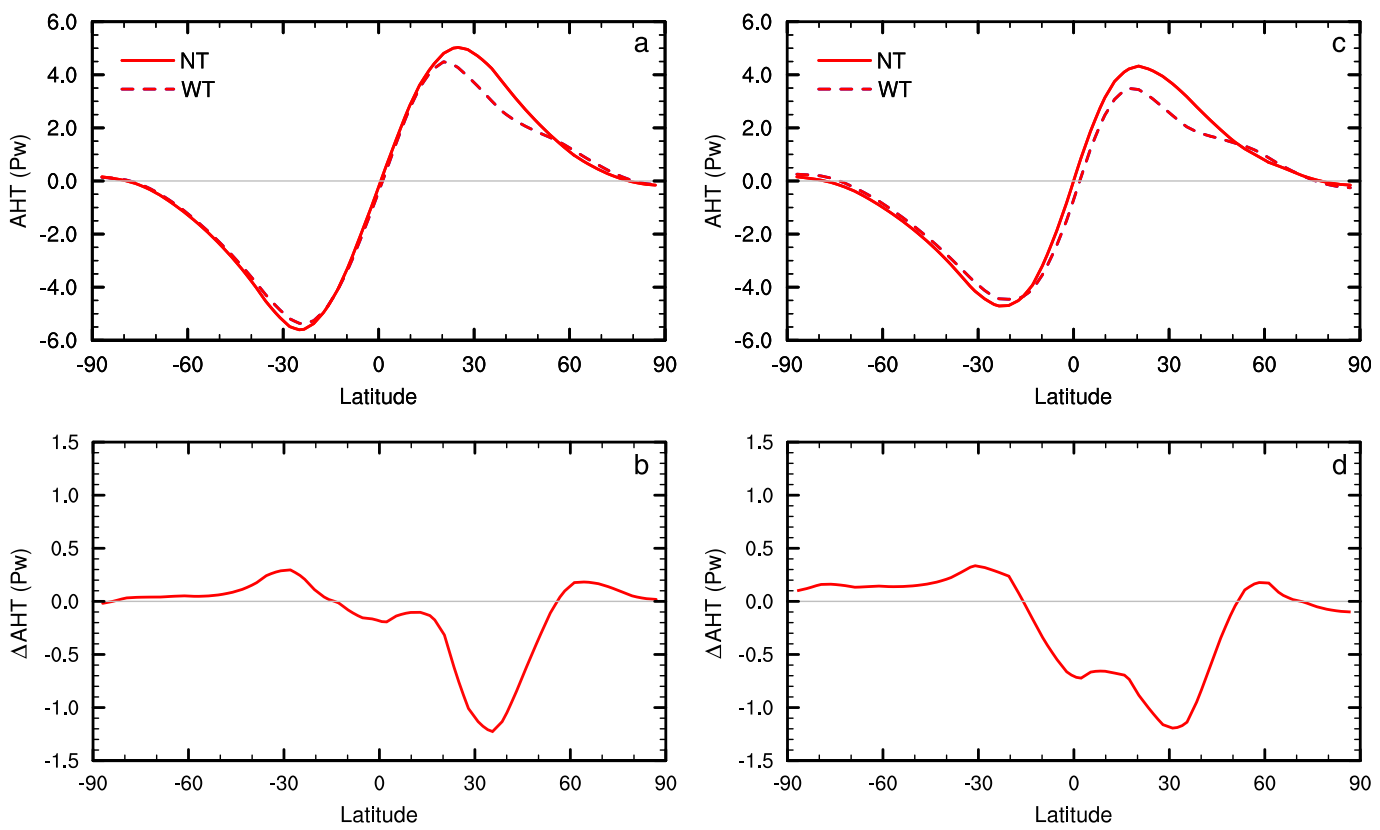

FIG. 16. As in Fig. 15, except the atmospheric heat transport is shown for the CAM3 simulations. Solar constant is $93 \%$ on the left and $90 \%$ on the right. The snow area on the Eurasian continent has already reduced dramatically for the $93 \%$ solar constant, so there is no clear contrast between the left and right panels.

they are not as efficient as the sea ice dynamics, at least when the system is in a near snowball Earth state.

\section{Conclusions}

We have investigated the influence of present-day continental topography on the initiation of a snowball Earth with an AOGCM, CCSM3. Results show that when $p \mathrm{CO}_{2}$ is relatively high, Earth's climate is colder if topography is present than if the topography is removed, even if the global mean surface elevation is the same. However when $p \mathrm{CO}_{2}$ is sufficiently low $(<140 \mathrm{ppmv})$, the relationship is reversed and Earth's climate is found to be more resistant to the onset of global glaciation when topography is present. When the solar insolation is $94 \%$ of present-day value, the critical $p \mathrm{CO}_{2}$ at the snowball Earth bifurcation point is $\sim 35 \mathrm{ppmv}$ in the presence of topography but $\sim 60 \mathrm{ppmv}$ in the absence of topography. This happens in the case of realistic modern topography because the Iranian Plateau, Anatolian Plateau, and Tibetan Plateau act as strong barriers to northward water vapor transport, so that less and less precipitation is received over the central region of the Eurasian continent when $p \mathrm{CO}_{2}$ significantly decreases. When climate is cold enough (e.g., $p \mathrm{CO}_{2} \leq 140$ ppmv), the snow cover over the central region of the Eurasian continent begins to disappear because precipitation becomes smaller than evaporation. The area of the exposed bare land expands as $p \mathrm{CO}_{2}$ is further decreased.
Because the bare land has much lower albedo than snow, this constitutes a negative feedback to the cooling induced by reducing $p \mathrm{CO}_{2}$. Such feedback does not exist when continents are flat and low. Because of this difference, an Earth with high continental topography does not necessarily have a cooler climate than one with low continental topography, as has traditionally been assumed.

The influence of topography on snowball Earth initiation therefore explains a large part of the difference between the results of Liu et al. (2013) and those of Yang et al. (2012a,b). These authors employed the same climate model, but with different continental configurations; Liu et al. (2013) used two different continental distributions appropriate for the Neoproteroic but no localized regions of high topography, whereas Yang et al. $(2012 a, b)$ used present-day continental distribution and topography. The critical $p \mathrm{CO}_{2}$ obtained by Liu et al. (2013) was $\sim 60-100 \mathrm{ppmv}$, and the annual-mean sea ice edge could reach only $\sim 24^{\circ}$ latitude in this critical state, whereas the values were found to be $\sim 17 \mathrm{ppmv}$ and $\sim 15^{\circ}$ latitude in Yang et al. (2012a,b). We show here that simply removing the topography in Yang et al. $(2012 \mathrm{a}, \mathrm{b})$ will approximately halve the critical value of $p \mathrm{CO}_{2}$ and shift the critical ice edge poleward by $\sim 6^{\circ}$ latitude. Preliminary results of further simulations indicate that the remaining difference may be due to the difference in aerosols between the assumptions in Liu et al. (2013) as compared to those in Yang et al. (2012a,b). 
Similar changes in snow cover as a function of atmospheric $p \mathrm{CO}_{2}$ are also observed in CAM3 simulations as in CCSM3 and result in a more significant surface warming $\left(\sim 10^{\circ} \mathrm{C}\right)$ in the northern portion of the Northern Hemisphere when topography is present than when it is removed. Because sea ice dynamics are not simulated in CAM3, however, the warming anomaly does not have any significant influence on the tropical sea ice growth. The tropical region is therefore always colder when topography is present than when it is removed, and a snowball Earth is initiated more easily. This demonstrates the importance of including the dynamics of sea ice when studying snowball Earth initiation. Neglecting this process not only overestimates the forcing required to initiate a snowball Earth (Voigt and Abbot 2012) but also masks the influence of continental topography on snowball Earth initiation.

The influence of topography on snowball Earth initiation will clearly depend on the geographical location of the Neoproterozoic supercontinent as well as the details of its topography, including the location of topographic extrema and their orientation and height. For example, the topography of the North American continent is unable to induce negative snow cover feedback in our CCSM3 simulations. For the Neoproterozoic era, even the geographical location of the supercontinents continues to be debated. No quantitative information is available as to what the topography within them might have been. It might reasonably be expected, however, that high mountainous regions were created during the assembly of the supercontinent Rodinia. The analyses presented herein suffice to suggest that the topography of the supercontinents could have played an important role in determining the conditions required for sea ice to entirely cover the equatorial ocean. This issue clearly warrants further investigation which will be described elsewhere.

Acknowledgments. The authors are grateful to R. P. Fiorella for the help on setting up the CAM3 runs. Y. Liu, J. Yang, and Y. Hu are supported by the Chinese-Israel Grant 41761144072. Y. Hu is supported by the National Natural Science Foundation of China under Grants 41375072 and 41530423 . The research of WRP at Toronto is supported by NSERC Discovery Grant A9627. All data analyzed in the paper are stored on a personal server and will be available upon request from the corresponding author.

\section{REFERENCES}

Abbot, D. S., I. Eisenman, and R. T. Pierrehumbert, 2010: The importance of ice vertical resolution for snowball climate and deglaciation. J. Climate, 23, 6100-6109, https://doi.org/ 10.1175/2010JCLI3693.1.
—, A. Voigt, M. Branson, R. T. Pierrehumbert, D. Pollard, G. Le Hir, and D. D. B. Koll, 2012: Clouds and Snowball Earth deglaciation. Geophys. Res. Lett., 39, L20711, https://doi.org/ 10.1029/2012GL052861.

Bahcall, J. N., M. H. Pinsonneault, and S. Basu, 2001: Solar models: Current epoch and time dependences, neutrinos, and helioseismological properties. Astrophys. J., 555, 990-1012, https:// doi.org/10.1086/321493.

Baum, S. K., and T. J. Crowley, 2001: GCM response to late Precambrian ( $\sim 590 \mathrm{Ma})$ ice-covered continents. Geophys. Res. Lett., 28, 583-586, https://doi.org/10.1029/2000GL011557.

Briegleb, B. P., C. M. Bitz, E. C. Hunke, W. H. Lipscomb, M. M. Holland, J. L. Schramm, and R. E. Moritz, 2004: Scientific description of the sea ice component in the Community Climate System Model, version 3. NCAR Tech. Note NCAR/TN-463+STR, 70 pp., https://doi.org/10.5065/ D6HH6H1P.

Budyko, M. I., 1969: Effect of solar radiation variations on climate of Earth. Tellus, 21, 611-619, https://doi.org/10.3402/ tellusa.v21i5.10109.

Chandler, M. A., and L. E. Sohl, 2000: Climate forcings and the initiation of low-latitude ice sheets during the Neoproterozoic Varanger glacial interval. J. Geophys. Res., 105, 20 737-20 756, https://doi.org/10.1029/2000JD900221.

Collins, W. D., and Coauthors, 2006: The Community Climate System Model version 3 (CCSM3). J. Climate, 19, 2122-2143, https://doi.org/10.1175/JCLI3761.1.

Donnadieu, Y., G. Ramstein, F. Fluteau, J. Besse, and J. Meert, 2002: Is high obliquity a plausible cause for Neoproterozoic glaciations? Geophys. Res. Lett., 29, 2127, https://doi.org/ 10.1029/2002GL015902.

— 'snowball Earth' climate triggered by continental break-up through changes in runoff. Nature, 428, 303-306, https://doi.org/ 10.1038/nature02408.

Feulner, G., and H. Kienert, 2015: Climate simulations of Neoproterozoic snowball Earth events: Similar critical carbon dioxide levels for the Sturtian and Marinoan glaciations. Earth Planet. Sci. Lett., 430, 551-552, https://doi.org/10.1016/ j.eps1.2015.09.006.

Fiorella, R. P., and C. J. Poulsen, 2013: Dehumidification over tropical continents reduces climate sensitivity and inhibits snowball Earth initiation. J. Climate, 26, 9677-9695, https:// doi.org/10.1175/JCLI-D-12-00820.1.

Galewsky, J., 2009: Rain shadow development during the growth of mountain ranges: An atmospheric dynamics perspective. J. Geophys. Res., 114, F01018, https://doi.org/10.1029/ 2008JF001085.

Goodman, J. C., 2006: Through thick and thin: Marine and meteoric ice in a "Snowball Earth" climate. Geophys. Res. Lett., 33, L16701, https://doi.org/10.1029/2006GL026840.

_ rine ice in "Snowball Earth." J. Geophys. Res., 108, 3308, https://doi.org/10.1029/2002JC001471.

Hoffman, P. F., and D. P. Schrag, 2000: Snowball earth. Sci. Amer., 282, 68-75, https://doi.org/10.1038/ scientificamerican0100-68.

— , and — 2002: The snowball Earth hypothesis: Testing the limits of global change. Terra Nova, 14, 129-155, https://oi.org/ 10.1046/j.1365-3121.2002.00408.x.

_ A. J. Kaufman, G. P. Halverson, and D. P. Schrag, 1998: A Neoproterozoic snowball Earth. Science, 281, 1342-1346, https://doi.org/10.1126/science.281.5381.1342. 
— , and Coauthors, 2017: Snowball Earth climate dynamics and Cryogenian geology-geobiology. Sci. Adv., 3, e1600983, https://doi.org/10.1126/sciadv.1600983.

Hyde, W. T., T. J. Crowley, S. K. Baum, and W. R. Peltier, 2000: Neoproterozoic 'snowball Earth' simulations with a coupled climate/ice-sheet model. Nature, 405, 425-429, https://doi.org/ 10.1038/35013005.

Jenkins, G. S., 2000: Global climate model high-obliquity solutions to the ancient climate puzzles of the Faint-Young Sun Paradox and low-latitude Proterozoic Glaciation. J. Geophys. Res., 105, 7357-7370, https://doi.org/10.1029/1999JD901125.

__ , and L. A. Frakes, 1998: GCM sensitivity test using increased rotation rate, reduced solar forcing and orography to examine low latitude glaciation in the Neoproterozoic. Geophys. Res. Lett., 25, 3525-3528, https://doi.org/10.1029/98GL52588.

— - and S. R. Smith, 1999: GCM simulations of Snowball Earth conditions during the late Proterozoic. Geophys. Res. Lett., 26, 2263-2266, https://doi.org/10.1029/1999GL900538.

Kirschvink, J. L., 1992: Late Proterozoic low latitude glaciation: The snowball Earth. The Proterozoic Biosphere: A MultiDisciplinary Study, J. W. Schopf, C. Klein, and D. Des Maris, Eds., Cambridge University Press, 51-52.

Lewis, J. P., A. J. Weaver, S. T. Johnston, and M. Eby, 2003: Neoproterozoic "snowball Earth": Dynamic sea ice over a quiescent ocean. Paleoceanography, 18, 1092, https://doi.org/ 10.1029/2003PA000926.

—, M. Eby, A. J. Weaver, S. T. Johnston, and R. L. Jacob, 2004: Global glaciation in the Neoproterozoic: Reconciling previous modelling results. Geophys. Res. Lett., 31, L08201, https://doi.org/ 10.1029/2004GL019725.

— A. A. Weaver, and M. Eby, 2007: Snowball versus slushball Earth: Dynamic versus nondynamic sea ice? J. Geophys. Res., 112, C11014, https://doi.org/10.1029/2006JC004037.

Liu, Y., and W. R. Peltier, 2010: A carbon cycle coupled climate model of Neoproterozoic glaciation: Influence of continental configuration on the formation of a "soft snowball." J. Geophys. Res., 115, D17111, https://doi.org/10.1029/2009JD013082.

— Neoproterozoic glaciation: Explicit carbon cycle with stochastic perturbations. J. Geophys. Res., 116, D02125, https:// doi.org/10.1029/2010JD015128.

,-- J. Yang, and G. Vettoretti, 2013: The initiation of Neoproterozoic "snowball" climates in CCSM3: The influence of paleocontinental configuration. Climate Past, 9, 2555-2577, https://doi.org/10.5194/cp-9-2555-2013.

,,,,---- and Y. Wang, 2016: Strong effects of tropical ice-sheet coverage and thickness on the hard snowball Earth bifurcation point. Climate Dyn., 48, 3459-3474, https:// doi.org/10.1007/s00382-016-3278-1.

Oglesby, R. J., and J. G. Ogg, 1999: The effect of large fluctuations in obliquity on climates of the late Proterozoic. Paleoclimates, 2, 293-316.

Peltier, W. R., L. Tarasov, G. Vettoretti, and L. P. Solheim, 2004: Climate dynamics in deep time: Modeling the "snowball bifurcation" and assessing the plausibility of its occurrence. The Extreme Proterozoic: Geology, Geochemistry, and Climate, G. S. Jenkins et al., Eds., American Geophysical Union, 107-124.

, Y. G. Liu, and J. W. Crowley, 2007: Snowball Earth prevention by dissolved organic carbon remineralization. Nature, 450, 813-818, https://doi.org/10.1038/nature06354.
Pollard, D., and J. F. Kasting, 2004: Climate-ice sheet simulations of Neoproterozoic glaciation before and after collapse to snowball Earth. The Extreme Proterozoic: Geology, Geochemistry, and Climate, G. S. Jenkins et al., Eds., Amer. Geophys. Union, 91-105.

$\longrightarrow$, and — 2005: Snowball Earth: A thin-ice solution with flowing sea glaciers. J. Geophys. Res., 110, C07010, https://doi.org/ 10.1029/2004JC002525.

_ and _ 2006: Reply to comment by Stephen G. Warren and Richard E. Brandt on "Snowball earth: A thin-ice solution with flowing sea glaciers." J. Geophys. Res., 111, C09017, https://doi.org/10.1029/2006JC003488.

Poulsen, C. J., and R. L. Jacob, 2004: Factors that inhibit snowball Earth simulation. Paleoceanography, 19, PA4021, https://doi.org/ 10.1029/2004PA001056.

- R. T. Pierrehumbert, and R. L. Jacob, 2001: Impact of ocean dynamics on the simulation of the Neoproterozoic "snowball Earth." Geophys. Res. Lett., 28, 1575-1578, https://doi.org/ 10.1029/2000GL012058.

— R. R. Jacob, R. T. Pierrehumbert, and T. T. Huynh, 2002: Testing paleogeographic controls on a Neoproterozoic snowball Earth. Geophys. Res. Lett., 29, 1515, https://doi.org/ 10.1029/2001GL014352.

Romanova, V., G. Lohmann, and K. Grosfeld, 2006: Effect of land albedo, $\mathrm{CO}_{2}$, orography, and oceanic heat transport on extreme climates. Climate Past, 2, 31-42, https://doi.org/10.5194/ cp-2-31-2006.

Rosenbloom, N., C. A. Shields, E. Brady, S. Yeager, and S. Levis, 2011: Using CCSM3 for paleoclimate applications. NCAR Tech. Note NCAR/TN-483+STR, 81 pp., https://doi.org/ 10.5065/D69S1P09.

Schrag, D. P., R. A. Berner, P. F. Hoffman, and G. P. Halverson, 2002: On the initiation of a snowball Earth. Geochem. Geophys. Geosyst., 3 (6), https://doi.org/10.1029/ $2001 \mathrm{GC} 000219$.

Voigt, A., and J. Marotzke, 2010: The transition from the presentday climate to a modern Snowball Earth. Climate Dyn., 35, 887-905, https://doi.org/10.1007/s00382-009-0633-5.

— Snowball Earth initiation and destabilize tropical sea-ice margins. Climate Past, 8, 2079-2092, https://doi.org/10.5194/ cp-8-2079-2012.

,,-- R. T. Pierrehumbert, and J. Marotzke, 2011: Initiation of a Marinoan Snowball Earth in a state-of-the-art atmosphere-ocean general circulation model. Climate Past, 7, 249-263, https://doi.org/10.5194/cp-7-249-2011.

Yang, J., W. R. Peltier, and Y. Y. Hu, 2012a: The initiation of modern "soft snowball" and "hard snowball" climates in CCSM3. Part I: The influences of solar luminosity, $\mathrm{CO}_{2}$ concentration, and the sea ice/snow albedo parameterization. J. Climate, 25, 2711-2736, https://doi.org/10.1175/ JCLI-D-11-00189.1.

— - , and $-2012 \mathrm{~b}$ : The initiation of modern "soft snowball" and "hard snowball" climates in CCSM3. Part II: Climate dynamic feedbacks. J. Climate, 25, 2737-2754, https:// doi.org/10.1175/JCLI-D-11-00190.1.

,-- , and,$- 2012 \mathrm{c}$ : The initiation of modern soft and hard Snowball Earth climates in CCSM4. Climate Past, 8, 907-918, https://doi.org/10.5194/cp-8-907-2012. 